\title{
High Precision Al-Mg Systematics of Forsterite-Bearing Type B CAIs from CV3 Chondrites
}

\author{
G. J. MacPherson ${ }^{1 *}$, E. S. Bullock ${ }^{1,2}$, T. J. Tenner ${ }^{3,4}$, D. Nakashima ${ }^{3,5}$, N. T. Kita ${ }^{3}$, \\ M. A. Ivanova ${ }^{1,6}$, A. N. Krot ${ }^{7}$, M. I. $\operatorname{Petaev}^{8}$, and S. B. Jacobsen ${ }^{8}$.
}

${ }^{1}$ Dept. of Mineral Sciences, Museum of Natural History, Smithsonian Institution, Washington, DC, USA 20560

${ }^{2}$ Carnegie Institution of Washington, Geophysical Laboratory, 5251 Broad Branch Rd., N.W., Washington, DC 20015

${ }^{3}$ WiscSIMS, University of Wisconsin, Madison, WI 53706, USA

${ }^{4}$ Los Alamos National Laboratory, Los Alamos, NM, 87545

${ }^{5}$ Tohoku University, Miyagi 980-8578, Japan

${ }^{6}$ Vernadsky Institute, Moscow, Kosygin St. 119991, Russia

${ }^{7}$ University of Hawai'i at Mānoa, Honolulu, Hawai'i 96822, USA

${ }^{8}$ Harvard University, Cambridge, Massachusetts 02138, USA

Submitted to: Geochimica et Cosmochimca Acta. April 8, 2016.

*E-mail of the corresponding author: Macphers@si.edu 
We dedicate this paper to our late colleague and friend Ian Hutcheon, who first showed how to properly measure magnesium isotopes with an ion microprobe.

Abstract. In order to further elucidate possible temporal relationships between different varieties of calcium-, aluminum-rich inclusions (CAIs), we measured the aluminum-magnesium isotopic systematics of seven examples of the rare type known as forsterite-bearing Type B (FoB) inclusions from four different CV3 carbonaceous chondrites: Allende, Efremovka, NWA 3118, and Vigarano. The primary phases (forsterite, Al-Ti-rich diopside, spinel, melilite, and anorthite) in each inclusion were analyzed in situ using high-precision secondary ion mass-spectrometry (SIMS). In all cases, minerals with low $\mathrm{Al} / \mathrm{Mg}$ ratios (all except anorthite) yield well-defined internal $\mathrm{Al}-\mathrm{Mg}$ isochrons, with a range of initial ${ }^{26} \mathrm{Al} /{ }^{27} \mathrm{Al}$ ratios $\left[\left({ }^{26} \mathrm{Al} /{ }^{27} \mathrm{Al}\right)_{0}\right]$ ranging from $(5.30 \pm 0.22) \times 10^{-5}$ down to $(4.17 \pm 0.43) \times 10^{-5}$. Anorthite in all cases is significantly disturbed relative to the isochrons defined by the other phases in the same CAIs, and in several cases contains no resolved excesses of radiogenic ${ }^{26} \mathrm{Mg}\left(\delta^{26} \mathrm{Mg}^{*}\right)$ even at ${ }^{27} \mathrm{Al} /{ }^{24} \mathrm{Mg}$ ratios greater than 1000. The fact that some FoBs preserve $\left({ }^{26} \mathrm{Al} /{ }^{27} \mathrm{Al}\right)_{0}$ of $\sim 5.2 \times 10^{-5}$, close to the canonical value of $(5.23 \pm 0.13) \times 10^{-5}$ inferred from bulk magnesium-isotope measurements of CV CAIs (Jacobsen et al., 2008), demonstrates that FoBs began forming very early, contemporaneous with other more-refractory CAIs. The range of $\left({ }^{26} \mathrm{Al} /{ }^{27} \mathrm{Al}\right)_{0}$ values further shows that FoBs continued to be reprocessed over $\sim 200,000$ years of nebular history, consistent with results obtained for other types of igneous CAIs in CV chondrites. The absence of any correlation between of $\mathrm{CAI}+\mathrm{FoB}$ formation or reprocessing times with bulk composition or CAI type means that there is no temporal evolutionary sequence between the diverse CAI types. The initial $\delta^{26} \mathrm{Mg}^{*}$ value in the most primitive FoB (SJ101) is significantly lower than the canonical solar system value of $-0.040 \pm 0.029 \%$.

\section{INTRODUCTION}

Forsterite-bearing Type B inclusions (FoBs) are an uncommon variety of igneous, coarsegrained Ca-, Al-rich inclusions (CAIs) that are found mainly in CV3 chondrites (e.g., Clayton et al., 1984; Wark et al., 1987; Davis et al., 1991; Krot et al., 2001 MacPherson et al., 2005; Petaev 
and Jacobsen, 2009; Bullock et al., 2012; Ivanova et al., 2012), and which contain igneous Carich forsterite in addition to the typical Type B CAI assemblage of melilite, Al-Ti-rich diopside, anorthite, and spinel.

FoBs are unusual for several reasons, including the fact that a disproportionate number of them have unusual isotopic properties (large degrees of mass-dependent fractionation in $\mathrm{O}, \mathrm{Mg}$, and $\mathrm{Si}$, and nucleosynthetic anomalies) relative to other CAIs (Clayton et al., 1984; Krot et al., 2014). Bullock et al. (2012) further showed that most FoBs preserve incontrovertible petrologic and isotopic evidence for having experienced melt evaporation from their surfaces, in some inclusions significant and in others minor. But one less-noted distinctive property of FoBs is their bulk composition. Despite so many similarities in texture and mineralogy (other than olivine) to Type B CAIs, the bulk compositions of most FoBs are closer to those of Al-rich chondrules (Bullock et al., 2012) and are Mg-rich and Al-poor relative to Type A and B CAIs. By analogy with the arguments presented by MacPherson and Huss (2005) for Al-rich chondrules, relative to Type A and B CAIs, FoB bulk compositions plot close to (but not exactly on) a lower-temperature portion of the equilibrium condensation trend for a gas of solar composition at $\sim 3 \times 10^{-3}$ atm total pressure (e.g., Yoneda and Grossman, 1995). The observation that CAI bulk compositions, including FoBs, mimic the trend of equilibrium condensation suggests the possibility of a time-temperature evolutionary sequence, but this need not be the case. For example, Type B CAIs are more "evolved" compositionally than are Type A CAIs in a monotonic condensation sequence, yet MacPherson et al. (2012) and Kita et al. (2013) showed that Types A and B CAIs overlap completely in their crystallization ages, and that both types experienced thermal processing in the nebula for $\sim 200,000$ years.

The relative age relationships between FoBs and other types of CAIs in CV chondrites, and the timing of their melt evaporation, are the subjects of this work. Here we report high-precision, individual mineral Al-Mg isotopic data in a suite of diverse FoBs with the goal of defining the initial $\left({ }^{26} \mathrm{Al} /{ }^{27} \mathrm{Al}\right)$ ratio $\left[\left({ }^{26} \mathrm{Al} /{ }^{27} \mathrm{Al}\right)_{0}\right]$ for each inclusion, and to compare their $\mathrm{Al}-\mathrm{Mg}$ relative age relationships to other types of CV CAIs. Preliminary results from this work were given in Bullock et al. (2014, 2015). 


\section{SAMPLES}

Thin sections of seven FoBs were analyzed: ALVIN, SJ101, and TS35-F1 from Allende, E60 and E64 from Efremovka, 3137-2 from Vigarano, and $4 N$ from NWA 3118. All of these objects except $4 N$ were illustrated and described in detail by Bullock et al. (2012), to which the reader is referred (including for details of mineral chemistry).

CAI $4 N$ is a disk-shaped object as seen in the meteorite prior to extraction, $11 \mathrm{~mm}$ in diameter and $\sim 2 \mathrm{~mm}$ thick. The thin section is illustrated in Figure 1. As is the case for most FoBs, $4 N$ is characterized by a very heterogeneous distribution of forsterite, to the extent that large portions of $4 N$ are olivine-free (Ivanova et al., 2014). Unlike some of the FoBs described by Bullock et al. (2012), however, the heterogeneity in $4 N$ is not related to core-mantle differences. Indeed, there is no obvious core-mantle structure in $4 N$ whatsoever. The inclusion is surrounded by Wark-Lovering rim layers (from inside outward) of melilite, anorthite, and Aldiopside with enclosed spinel and rare forsterite grains. The primary mineralogy of $4 \mathrm{~N}$ consists of abundant Ti-poor Al-diopside $\left(\mathrm{Al}_{2} \mathrm{O}_{3}\right.$ 7.8-14.8 wt. \%; $\mathrm{TiO}_{2}$ 1.5-3.0 wt. \%), spinel, Ca-rich forsterite $\left(\mathrm{Fo}_{97-99}, 1.2-1.5\right.$ wt. \% $\left.\mathrm{CaO}\right)$, sparse melilite and anorthite, and rare grains of $\mathrm{Fe}, \mathrm{Ni}-$ metal and sulfides. Most anorthite crystals are partially replaced by nepheline and sodalite. Melilite compositions are tri-modal: interior melilite enclosed within palisades of spinel is very åkermanitic ( $\AA^{k_{85}-87}$ ), whereas those crystals not enclosed by spinel are somewhat more gehlenitic $\left(\AA_{k_{39-69}}\right)$. Melilite in the Wark-Lovering rim sequence is very gehlenitic, $\left(\AA_{k_{6-8}}\right)$. In the spectrum of FoB reprocessing as documented by Bullock et al. (2012), $4 \mathrm{~N}$ is minimally reprocessed and most similar to ALVIN.

\section{ANALYTICAL METHODS}

The petrography and mineral chemistry of all the CAIs were analyzed at the Smithsonian Institution using scanning electron microscopy (SEM) and electron probe microanalysis, via techniques described in Bullock et al. (2012). Candidate grains for SIMS study were selected and carefully documented prior to isotopic analysis. 
Aluminum-magnesium isotopic analyses were performed using the WiscSIMS Cameca IMS 1280 at the University of Wisconsin-Madison, utilizing a monocollection electron multiplier (EM) configuration for anorthite and gehlenitic melilite and a multicollection setup with Faraday cups (FC) for low $\mathrm{Al} / \mathrm{Mg}$ phases (melilite, spinel, Al-diopside, and forsterite). The general analytical procedure is described in Kita et al. (2012), with project-specific details given below. Data were corrected for intrinsic mass-dependent fractionation using an exponential law with $\beta=$ 0.5128 (Davis et al., 2015). After SIMS analysis, each ion probe pit was imaged using an SEM to check for any overlap onto other mineral phases or cracks, which, if found, led to their rejection.

2.1 Multicollection FC analyses: The primary $\mathrm{O}^{-}$beam was tuned to a uniform oval shape $(0.8$ aspect ratio; Köhler illumination) using mass apertures and beam apertures in the primary column. The primary beam diameter and intensity were optimized for each phase and grain size by applying different combinations of aperture sizes, which increased somewhat during the session due to sputtering by the primary beam. The spot sizes (long dimension) and conditions were as follows: $\sim 10 \mu \mathrm{m}(1.5-4 \mathrm{nA})$ for olivine, spinel and some melilite analyses, $15-20 \mu \mathrm{m}$ (13-18 nA) for most melilite and pyroxene analyses, and $\sim 30 \mu \mathrm{m}(25 \mathrm{nA})$ for some coarsegrained pyroxene. Each analysis duration was $\sim 8 \mathrm{~min}$. Matrix matched Mg-isotope standards of olivine, spinel, fassaite glass and melilite glass (with known $\delta^{25} \mathrm{Mg}$ values except for spinel; Kita et al., 2012; Ushikubo et al., 2012) were analyzed multiple times during each session in order to bracket unknown analyses. The external reproducibility (2SD) of $\delta^{25} \mathrm{Mg}$ analysis was typically $0.1-0.2 \%$ for these standards except for $\sim 0.3 \%$ for Al-rich melilite. The external reproducibility of $\delta^{26} \mathrm{Mg} *$ in the standards was $0.07-0.15 \%$ for olivine, spinel, Mg-rich melilite and coarsegrained pyroxene analyses, while that of melilite analyses using a smaller beam was typically $0.2-0.3 \%$ for Mg-rich melilite and degraded to $\sim 0.7 \%$ for Al-rich melilite. The internal errors of each standard analysis are generally similar to or slightly worse than those of external reproducibility given above, so that final uncertainties of unknown analyses are assigned to the external reproducibility of matrix matching standard that bracket the unknown analyses.

2.2 Monocollection EM analyses: Using Köhler illumination, $5 \mu \mathrm{m}(20-60 \mathrm{pA})$ and $10 \mu \mathrm{m}(0.7$ $\mathrm{nA}$ ) diameter beam spots were employed for Al-rich melilite and anorthite analyses, respectively, although some smaller anorthite crystals required $5 \mu \mathrm{m}$ beam spots. Magnesium isotopes were detected using EM by peak jumping, while ${ }^{27} \mathrm{Al}^{+}$ions were detected using multicollection FC 
simultaneously with ${ }^{25} \mathrm{Mg}+$ ions. An EM dead time correction of $23 \mathrm{~ns}$ was applied to all $\mathrm{Mg}$ isotope signals. Acquisition times for ${ }^{24} \mathrm{Mg},{ }^{25} \mathrm{Mg}$, and ${ }^{26} \mathrm{Mg}$ were $2 \mathrm{~s}, 10 \mathrm{~s}$, and $10 \mathrm{~s}$, respectively. Including waiting time for switching magnetic fields, 1 cycle took 30s. Anorthite analyses $\left({ }^{27} \mathrm{Al} /{ }^{24} \mathrm{Mg} \sim 200-1,000\right)$ were 50 cycles each and took $\sim 30 \mathrm{~min}$. Melilite analyses $\left({ }^{27} \mathrm{Al} /{ }^{24} \mathrm{Mg}\right.$ 10-30) were 100-200 cycles each and took 1-2 hours.

The precision of $\delta^{26} \mathrm{Mg}^{*}$ was $2-20 \%$ for anorthite and $1-2 \%$ for melilite. Two anorthite glass standards (with $\mathrm{MgO}=0.1$ and 1\%), and a melilite glass standard ( $\AA_{15}$ ) (Kita et al., 2012) were repeatedly analyzed throughout each session, to bracket unknown analyses.

\section{RESULTS}

Isotopic data are given in Table A1 (Appendix A) and are shown graphically as isochron diagrams in Figures 2-4, the latter showing separate plots for low Al/Mg phases (left side) and anorthite (right side). All isochron slopes were calculated using Isoplot Model-1 fits. Figures 5-6 show mass-dependent fractionation data $\left(\delta^{25} \mathrm{Mg}\right)$ for each $\mathrm{CAI}$, and again the data for low $\mathrm{Al} / \mathrm{Mg}$ phases and anorthite are shown separately in the left and right sides respectively. In all of the isochron plots in Figures 2-4, the anorthite points plot significantly below the isochrons defined by spinel, pyroxene, and spinel. Conversely, in some cases the most Mg-rich melilite scatters above this isochron. Anorthite is well-known to be more susceptible to isotopic exchange than some other CAI phases, especially in contact with spinel (MacPherson et al., 2012). We consider both observations in combination to be indicative of partial isotopic disturbance of the kind described by Podosek et al. (1991), in which high-Al/Mg phases such as anorthite exchange with low $\mathrm{Al} / \mathrm{Mg}$ phases - in this case Mg-rich melilite. Because the anorthite consistently falls below the isochrons defined by other phases, anorthite was not included in the isochron slope calculations. In cases where the Mg-rich melilite points scattered excessively (in some cases outside of error limits), we found that excluding those melilite points significantly improved the isochron MSWD as well as the probability of fit. In such cases, we excluded the Mg-rich melilite in calculating the isochron slopes; those points are shown in Figures 2-4 with different symbols than those used for the more aluminous melilite. Results for each CAI are given in the order from the least evaporated through to the most evaporated object, as estimated from petrologic criteria by Bullock et al. (2012). A summary of all isochron slopes is given in Table 1 . 
$\delta^{26} \mathrm{Mg}^{*}$ vs. ${ }^{27} \mathrm{Al} /{ }^{24} \mathrm{Mg}$

SJ101 (Fig. 2): Spinel and pyroxene show resolved $\delta^{26} \mathrm{Mg}^{*}$ excesses that correlate with ${ }^{27} \mathrm{Al} /{ }^{24} \mathrm{Mg}$ ratio. An Isoplot model-1 isochron based on those phases, plus åkermanitic melilite and forsterite, yields $\left({ }^{26} \mathrm{Al} /{ }^{27} \mathrm{Al}\right)_{0}$ of $(5.20 \pm 0.53) \times 10^{-5}$ with an intercept (initial $\left.\delta^{26} \mathrm{Mg} *\right)$ of $-0.128 \pm 0.037 \%$ (Fig. 2a). Although the mean square of weighted deviates (MSWD) is low (0.48; Fig. 2a), the probability of fit is $96 \%$ and we consider the isochron to be robust. There is no aluminous melilite or Al-rich pyroxene within the inclusion, so the isochron slope is largely constrained by spinel $\left({ }^{27} \mathrm{Al} /{ }^{24} \mathrm{Mg}\right.$ of $\left.\sim 2.5\right)$, and the uncertainly is relatively large. Within this uncertainty, the slope of the isochron is indistinguishable from that of the whole CAI CV3 isochron of $(5.23 \pm 0.13) \times 10^{-5}$ (B. Jacobsen et al., 2008). Also shown (in red) on Figure $2 \mathrm{a}$ is the bulk isotopic composition of SJ101, as determined via MC-ICP-MS (S. B. Jacobsen et al., 2008), and which lies close to the canonical isochron. However, our internal isochron does not pass through this bulk value but instead is displaced by $\sim 0.15 \%$ below it. Also shown on Figure $2 \mathrm{a}$ are the bulk ${ }^{27} \mathrm{Al} /{ }^{24} \mathrm{Mg}$ values for $S J 101$ as calculated from wide-area X-ray mapping done by both EDS and electron microprobe. These latter two values are similar to one another but differ from the ICP-MS value in the direction of higher ${ }^{27} \mathrm{Al} /{ }^{24} \mathrm{Mg}$; they are within error of our internal isochron. We attribute these differences to non-representative sampling of this very heterogeneous object for the ICP-MS measurements. Anorthite in SJ101 (Fig. 2b) shows resolved excess $\delta^{26} \mathrm{Mg}^{*}$, but the data systematically plot below the isochron defined by the low Al/Mg phases (Fig. 2a). Only $80 \mathrm{mg}$ (Petaev and Jacobsen, 2009) of this > 6 gram CAI were dissolved to make the ICP-MS solution, and under-representation of anorthite in that sample would lower the measured ${ }^{27} \mathrm{Al} /{ }^{24} \mathrm{Mg}$. Regardless, the $\delta^{26} \mathrm{Mg}_{0}$ intercept of our internal isochron $\left(\delta^{26} \mathrm{Mg}_{0}=-0.128 \pm 0.037\right.$, as defined by low $\mathrm{Al} / \mathrm{Mg}$ phases $)$ is significantly lower than that of the canonical line. $\delta^{26} \mathrm{Mg}_{0}=-0.040 \pm 0.029 \%$ (B. Jacobsen et al., 2008). This discrepancy is discussed below.

ALVIN (Fig. 2): Data for forsterite, pyroxene, spinel, and one åkermanitic melilite grain define a model-1 internal $\mathrm{Al}-\mathrm{Mg}$ isochron (Fig. 2c) with $\left({ }^{26} \mathrm{Al} /{ }^{27} \mathrm{Al}\right)_{0}$ of $(4.17 \pm 0.43) \times 10^{-5}$ and initial $\delta^{26} \mathrm{Mg}^{*}=-0.092 \pm 0.029 \%$. As in the case for SJ101, the MSWD for ALVIN is low (0.48) but the probability of fit is $97 \%$, so we consider this isochron also to be reasonably robust. The 
isochron slope for ALVIN is significantly lower than the canonical value, as is the $\delta^{26} \mathrm{Mg}_{0}$. The single anorthite analysis shows no resolvable excess $\delta^{26} \mathrm{Mg}^{*}$ (Fig. 2d).

$4 N$ (Fig. 2): Pyroxene, spinel, forsterite and anorthite were measured in $4 N$. An internal model-1 Al-Mg isochron based on olivine, pyroxene, and spinel has a slope of $(4.70 \pm 0.32) \times 10^{-5}$, with initial $\delta^{26} \mathrm{Mg}^{*}=-0.005 \pm 0.027 \%$ (Fig. 2e). The MSWD is low (0.48) and the probability of fit is $96 \%$, so we consider this isochron also to be robust. The inferred $\left({ }^{26} \mathrm{Al} /{ }^{27} \mathrm{Al}\right)_{0}$ is slightly lower than the canonical value. The anorthite data all show excess $\delta^{26} \mathrm{Mg} *$ but plot below the isochron determined by the low $\mathrm{Al} / \mathrm{Mg}$ phases (Fig. 2f).

E64 (Fig. 3): The Al-Mg isotope data for forsterite, pyroxene, spinel, and melilite $\left({ }^{27} \mathrm{Al} /{ }^{24} \mathrm{Mg}\right.$ up to 7) define an internal ${ }^{26} \mathrm{Al}-{ }^{26} \mathrm{Mg}$ isochron of slope of $(5.20 \pm 0.35) \times 10^{-5}$ and initial $\delta^{26} \mathrm{Mg}^{*}=$ $0.089 \pm 0.045 \%$ (Fig. 3a). The MSWD for E64 is 0.63 and the probability of fit is $90 \%$, so this isochron is considered to be robust. Within uncertainties, the $\left({ }^{26} \mathrm{Al} /{ }^{27} \mathrm{Al}\right)_{0}$ value is indistinguishable from the canonical value. Anorthite analyses have no resolvable excess $\delta^{26} \mathrm{Mg} *$ (Fig. 3b).

E60 (Fig. 3): E60 is one of two cases where data from the very Mg-rich melilite show considerable scatter although, in this case, those data are (marginally) within analytical uncertainty of each other. Forsterite, pyroxene, spinel, and all melilite data yield a Model-1 isochron with $\left({ }^{26} \mathrm{Al} /{ }^{27} \mathrm{Al}\right)_{0}$ of $(5.14 \pm 0.30) \times 10^{-5}$, with MSWD $=1.8$ and probability of fit $=0$. Using a Model-2 fit, gives $\left({ }^{26} \mathrm{Al} /{ }^{27} \mathrm{Al}\right)_{0}$ of $(5.40 \pm 0.15) \times 10^{-5}$, and $\delta^{26} \mathrm{Mg}_{0}=-0.030 \pm 0.056 \%$ with $\mathrm{MSWD}=1.8$. However, if only the more aluminous melilites are included $\left({ }^{27} \mathrm{Al} /{ }^{24} \mathrm{Mg}>\sim 1\right)$, a Model-1 fit yields $\left({ }^{26} \mathrm{Al} l^{27} \mathrm{Al}\right)_{0}$ of $(5.30 \pm 0.22) \times 10^{-5}$, and $\delta^{26} \mathrm{Mg}_{0}=-0.081 \pm 0.030 \%$ (Fig. 3c), with MSWD $=1.11$ and probability of fit $33 \%$. Both anorthite analyses show excess $\delta^{26} \mathrm{Mg}^{*}$, but plot well below any possible isochrons (above) defined by the low Al/Mg minerals (Fig. 3d). As we note in the Discussion, the systematically-displaced data for the Mg-rich melilite and anorthite in this CAI and Vigarano 3137-2 are consistent with isotopic disturbance caused by exchange between Mg-rich and Mg-poor phases, Therefore, rejecting the anorthite and Mg-rich melilite data from our isochron regressions not only makes sense, but it suggests how disturbed but highly precise SIMS Al-Mg isochron data can be treated in the future. We accordingly adopt $\left({ }^{26} \mathrm{Al} /{ }^{27} \mathrm{Al}\right)_{0}=(5.30 \pm 0.22) \times 10^{-5}$, for the isochron slope (Table1), which is within error of the canonical value of B. Jacobsen et al. (2008). E60 was previously studied by Amelin et al. (2002) 
and Wadhwa et al. (2009). Amelin et al. (2002) reported an internal Al-Mg isochron with $\left({ }^{26} \mathrm{Al} /{ }^{27} \mathrm{Al}\right)_{0}=(4.63 \pm 0.44) \times 10^{-5}$. However, their isochron included anorthite in the regressions whereas ours does not; their data without the anorthite is too scattered and the error bars are too large to give a meaningful result. Later LA-ICP-MS analyses of E60 by Wadhwa et al. (2009) also give a lower slope than our data, $\left({ }^{26} \mathrm{Al} /{ }^{27} \mathrm{Al}\right)_{0}=(3.2 \pm 0.35) \times 10^{-5}$, but again included anorthite in the regression. The fact that our data excepting anorthite define a coherent isochron of higher slope, and that only anorthite deviates significantly from this line, suggests that the differences in inferred $\left({ }^{26} \mathrm{Al} /{ }^{27} \mathrm{Al}\right)_{0}$ between our study and the previous studies is due mainly to the anorthite having been partially reset (discussed below). Thus we did not include the anorthite data in calculating our value for $\left({ }^{26} \mathrm{Al} /{ }^{27} \mathrm{Al}\right)_{0}$.

3137-2 (Fig. 3): An internal Al-Mg isochron defined by olivine, spinel, pyroxene, and all melilite data gives $\left({ }^{26} \mathrm{Al} /{ }^{27} \mathrm{Al}\right)_{0}=(4.54 \pm 0.40) \times 10^{-5}$ and initial $\delta^{26} \mathrm{Mg} *=0.055 \pm 0.035 \%$, with MSWD of 1.9. However the magnesium-rich melilite data show significant scatter, and two data points plot above the regression line outside of analytical uncertainty. This is reflected in the MSWD of 1.9. Omitting the Mg-rich melilite data from the regression gives a model-1 fit of $\left({ }^{26} \mathrm{Al} /{ }^{27} \mathrm{Al}\right)_{0}=(4.76 \pm 0.35) \times 10^{-5}$ and initial $\delta^{26} \mathrm{Mg}^{*}=0.007 \pm 0.038 \%$, with MSWD of 1.30 and a probability of fit of $18 \%$. We adopt the latter value here (Table 1), and which is shown in Figure 3e along with the rejected points denoted by filled triangles. The slope of the isochron is just barely within error of the canonical value. Both anorthite analyses yield no resolvable excess $\delta^{26} \mathrm{Mg}^{*}$ (Fig. 3f). MacPherson \& Davis (1992) previously studied 3137-2, and they likewise found no excess $\delta^{26} \mathrm{Mg} *$ in anorthite.

TS35-F1 (Fig. 4): This FoB exhibits the largest degree of surface melt evaporation (Bullock et al., 2012; and see below) of any of the objects we studied, a consequence of which is that melilite in its outer mantle is far more gehlenitic $\left({ }^{27} \mathrm{Al} /{ }^{24} \mathrm{Mg}\right.$ up to $\left.\sim 26\right)$ than melilite in any of the other FoBs we studied. The model-1 isochron defined by olivine, spinel, pyroxene, and melilite gives $\left({ }^{26} \mathrm{Al} /{ }^{27} \mathrm{Al}\right)_{0}=(4.69 \pm 0.28) \times 10^{-5}$ and initial $\delta^{26} \mathrm{Mg}^{*}=-0.068 \pm 0.070 \pm 0.031 \%$. The MSWD is 1.011 and the probability of fit is $45 \%$, so we consider this isochron to be robust. The isochron slope is marginally resolved from and lower than the canonical value, as is the $\delta^{26} \mathrm{Mg}_{0}$. Note that the most aluminous melilite plots (within large errors) of the same isochron as do the Mg-rich melilites. Anorthite analyses have small to no excesses of $\delta^{26} \mathrm{Mg}^{*}$ (Fig. 4b). 
$\delta^{25} M g$

The most striking aspect of the mass-dependent isotopic fractionation signatures in these seven CAIs is that they are so different. Recall that in our analytical protocol, we do each mineral sequentially rather than each CAI sequentially. Thus, for example, all pyroxene analyses for all the CAIs are done at the same time, then the second phase, and so forth. Thus the observation that all phases in $S J 101$ have $\delta^{25} \mathrm{Mg}$ close to or less than zero whereas the phases in $3137-2$ all show $\delta^{25} \mathrm{Mg}$ significantly greater than zero cannot be attributed to any kind of analytical artifact. These differences are real.

SJ101 (Fig. 5): All phase except spinel have $\delta^{25} \mathrm{Mg}<-1 \%$, with melilite being slightly less negative than pyroxene and olivine intermediate between the two. Spinel has $-1 \%_{0}<\delta^{25} \mathrm{Mg}<1 \%$. Anorthite shows $\delta^{25} \mathrm{Mg}$ slightly less than but within error of zero.

ALVIN (Fig. 5) is similar to $S J 101$ in most respects but has higher (less negative) $\delta^{25} \mathrm{Mg}$ overall. Melilite, pyroxene, and olivine all show $-1 \% \%_{0}<\delta^{25} \mathrm{Mg}<0 \%$, but spinel is consistently higher and positive with $1 \%<<\delta^{25} \mathrm{Mg}<4 \%$. The single anorthite analysis is within error of zero.

$4 N$ (Fig. 5) is similar to ALVIN but has higher overall $\delta^{25} \mathrm{Mg}$ in pyroxene and olivine, close to but slightly greater than zero. Spinel is again positive and greater than the other phases, $1 \%<$ $\delta^{25} \mathrm{Mg}<4 \%$. Anorthite is mostly within error of zero.

E64 (Fig. 6) is unlike the previous three FoBs. All phases except anorthite have consistently positive $\delta^{25} \mathrm{Mg}$, with olivine tightly clustered close to $\delta^{25} \mathrm{Mg}=11 \%$ pyroxene also tightly clustered close to $\delta^{25} \mathrm{Mg}=10 \%$, aluminous melilite consistently lower at $\delta^{25} \mathrm{Mg}=\sim 1 \%{ }_{0}-4 \%$, and spinel highly variable with $\delta^{25} \mathrm{Mg}=\sim 6 \%{ }_{0}-14 \%$. Anorthite again has large error bars but is consistently within error of zero.

E60 (Fig. 6) is broadly similar in pattern to $E 64$ but lower overall in $\delta^{25} \mathrm{Mg}$. Olivine is in the range $\delta^{25} \mathrm{Mg}=4 \%{ }_{0}-4.5 \%$, pyroxene has $\delta^{25} \mathrm{Mg}=2.5 \%$ o-4\%o, Mg-rich melilite has $\delta^{25} \mathrm{Mg}=$ $0 \%-3 \%$, and Al-rich melilite has $-1 \% 0 \leq \delta^{25} \mathrm{Mg} \leq 0 \%$.

$3137-2$ (Fig. 6) is the most nearly homogeneous FoB in terms of $\delta^{25} \mathrm{Mg}$. All phases, including even anorthite have consistently positive $\delta^{25} \mathrm{Mg}$ and within a fairly narrow range: 
olivine $\delta^{25} \mathrm{Mg}$ close to $6 \%$, pyroxene $\delta^{25} \mathrm{Mg}$ also close to $6 \%$, melilite $\delta^{25} \mathrm{Mg}=\sim 6.5 \%$ o $-8 \%$, spinel $\delta^{25} \mathrm{Mg}$ close to $8 \%$, and anorthite (with the usual large error bars) close to $5 \%$.

Alone of the FoBs we analyzed, TS35-F1 (Fig. 6) has a mass-dependent isotopic fractionation pattern that is broadly consistent simple surface evaporation of a partially molten droplet (discussed below). Aluminous melilite, all occurring exclusively in the outer mantle of the CAI, has $\delta^{25} \mathrm{Mg}$ in the approximate range $4 \% \%^{-7 \%}$; this is greater than any other phases in this CAI excepting only one spinel point. Most spinel is in the range $\delta^{25} \mathrm{Mg}=2.5 \%{ }_{0}-3.5 \%$, but the one extreme point is close to $\delta^{25} \mathrm{Mg}=9 \%$. Pyroxene and olivine overlap, in the range $\delta^{25} \mathrm{Mg}$ $=0 \%{ }_{0}-2 \%$ Anorthite is in the approximate range $\delta^{25} \mathrm{Mg}=0 \%{ }_{0}-10 \%$ with large error bars.

\section{DISCUSSION}

\section{Al-Mg relative chronology of FoBs compared to other CAI varieties}

One of the main goals of this study was to determine if times of FoB formation and nebular processing, as inferred from initial ${ }^{26} \mathrm{Al} /{ }^{27} \mathrm{Al}$ ratios, are similar to or different from those of other CAI varieties. The question naturally arises because of the distinctly different bulk chemistry of the FoBs from other CAI types and, equally, their compositional similarity to Alrich chondrules. Isotopic evidence indicates that many chondrules, including the Al-rich varieties, formed 1-3 million years after CAIs did (e.g., Amelin et al., 2002; Kita et al., 2012). Thus Al-Mg isotopic systematics are an obvious means of testing whether FoBs are more closely related to other CAIs or instead to chondrules. Another motivation for this study was to determine if the initial ${ }^{26} \mathrm{Al} /{ }^{27} \mathrm{Al}$ ratios in FoBs are similar to or else systematically different from more common CAI varieties. In the context of equilibrium condensation models for the early solar nebula (e.g., Grossman, 1972), forsterite condenses at a somewhat lower temperature than any of the usual CAI phases such as melilite and spinel and calcic pyroxene. If the forsterite enrichment of FoBs represents a greater sampling of lower temperature condensates relative to other CAI types, that could (albeit not necessarily) imply later precursor accretion and melting, after cooling of the gas to a somewhat lower temperature.

Our data collected from pyroxene, spinel, olivine, and melilite show that the FoBs we analyzed exhibit the same range in $\left({ }^{26} \mathrm{Al} /{ }^{27} \mathrm{Al}\right)_{0}$ as do Types $\mathrm{A}$ and $\mathrm{B} \mathrm{CAIs}$, from $\sim 5.2 \times 10^{-5}$ to 
$\sim 4.2 \times 10^{-5}$, and differ significantly from the values commonly found in chondrules, (typically $<1 \times 10^{-5}$ ). Prior to considering the chronologic implications of our results relative to the stated goals, however, we must show that any such chronologic implication are justified. First, we are assuming that we can use initial ${ }^{26} \mathrm{Al} /{ }^{27} \mathrm{Al}$ as a valid relative chronometer at least for dating $\mathrm{CV}$ CAIs.. In the case of FoBs from CV3 chondrites, that assumption is justified as follows. The existence of inclusions with Fractionation and Unknown Nuclear effects (FUN CAIs; Wasserburg et al., 1977) and platy hibonite crystals (PLACs; Ireland et al., 1988; Kööp et al, 2016) - one of whose characteristics is the absence or near-absence of ${ }^{26} \mathrm{Al}$ at the time of their formation - demonstrates unequivocally that the early solar nebula was not isotopically homogeneous. This fact is the primary reason for questioning whether initial ${ }^{26} \mathrm{Al} /{ }^{27} \mathrm{Al}$ can be used as a valid relative chronometer. However, FUN CAIs are very rare in CV3 chondrites. Considering only CAIs from CV3 chondrites, the whole-CAI isochrons of B. Jacobsen et al. (2008) and Larsen et al. (2011) basically require that the non-FUN CV3 CAI precursors formed over a very short time interval ( $<20,000$ years) and from a reservoir that was homogeneously enriched in ${ }^{26} \mathrm{Al}$. Thus, although isotopic heterogeneity may have existed nebula-wide early on, the region where most CV3 CAIs formed was isotopically very homogeneous. Only the FUN CAIs are different. Therefore, considering only non-FUN CV3 CAIs, variations among CAIs (in the present case, FoBs) in initial ${ }^{26} \mathrm{Al} /{ }^{27} \mathrm{Al}$ record the relative chronology of events that occurred subsequent to formation of such CAI precursors. Nebula-wide isotopic heterogeneity - of obvious importance in the large scale - is irrelevant to the goals of this paper.

A second possible problem for interpreting our isotopic data as isochrons arises from our model for the formation of FoBs as heterogeneous aggregates of forsterite-poor and forsteriterich refractory material that underwent varying degrees of partial melting and melt evaporation (Bullock et al., 2012). Specifically, one might question whether the "isochrons" for the least evaporated FoBs (SJ101, ALVIN, $4 N$ ) really are true isochrons. ALVIN is relatively primitive only in the sense that it did not experience much surface melt evaporation (in contrast with e.g., TS35-F1 and 3137-2), but otherwise it is a predominantly igneous object. That leaves only SJ101 and $4 N$ in any doubt, but the essential point is that even these objects did undergo sufficient partial melting to produce igneous textures at least locally without destroying the original aggregate structure consisting of olivine-rich and olivine-free material. Additionally, Bullock et 
al. (2012) showed that the texturally-inferred crystallization sequences of these FoBs broadly match those expected from igneous crystallization of melts of their respective bulk compositions. Thus, we conclude that all of the studied FoBs are igneous and that the data arrays in Figures 2-5 are true isochrons.

In light of the above, we can now address the chronological implications of our data. Like our current results for FoBs, high-precision SIMS internal isochrons from other types of CV3 CAIs also yield a range of initial ${ }^{26} \mathrm{Al} /{ }^{27} \mathrm{Al}$ values. The most primitive (unmelted) CAIs, such as Fluffy Type As and spinel-rich fine-grained inclusions, consistently yield $\left({ }^{26} \mathrm{Al} /{ }^{27} \mathrm{Al}\right)_{0} \sim 5 \times 10^{-5}$, essentially identical to Jacobsen et al.'s (2008) the solar-system initial value (MacPherson et al., 2012). In contrast, CAIs that experienced mild to extensive partial remelting, such as the Compact Type A and Type B CAIs, exhibit a range of $\left({ }^{26} \mathrm{Al} /{ }^{27} \mathrm{Al}\right)_{0}$ from $\sim 5.2 \times 10^{-5}$ to $\sim 4.2 \times 10^{-5}$ (MacPherson et al., 2012; Kita et al., 2013). The overall range corresponds to melting and remelting of the CAI precursors over a span of $\sim 200,000$ years after their initial formation. As we have demonstrated herein, the inferred $\left({ }^{26} \mathrm{Al} /{ }^{27} \mathrm{Al}\right)_{0}$ values for FoBs have a nearly identical range as those of Types A and B CAIs, which also corresponds to melting and solidification over a 200,000 year time period. These and our previous data for a variety of CAI types are summarized in Figure 7, showing the complete overlap in the range of $\left({ }^{26} \mathrm{Al} /{ }^{27} \mathrm{Al}\right)_{0}$ between FoBs and Types A and B CAIs. Note also, however, that there is no correlation between the degree of melting in the FoBs and $\left({ }^{26} \mathrm{Al} /{ }^{27} \mathrm{Al}\right)_{0}$. The two least-melted and least-evaporated FoBs, SJ101 and $A L V I N$, have $\left({ }^{26} \mathrm{Al} /{ }^{27} \mathrm{Al}\right)_{0}$ ratios of $(5.20 \pm 0.53) \times 10^{-5}$ and $(4.17 \pm 0.43) \times 10^{-5}$, respectively. The other five FoBs (including the most reprocessed example, TS35-F1) have intermediate values. As there is no bulk CAI isotopic data to indicate that any CAI precursors formed subsequent to $\left({ }^{26} \mathrm{Al} /{ }^{27} \mathrm{Al}\right)_{0}=(5.23 \pm 0.13) \times 10^{-5}$, the implication is that any range in $\left({ }^{26} \mathrm{Al} /{ }^{27} \mathrm{Al}\right)_{0}$ ratios among ${ }^{26} \mathrm{Al}$-rich igneous CAIs reflects timing of reprocessing: mainly, melting. Accordingly, the fact that FoBs exhibit a well-resolved and wide range of initial ${ }^{26} \mathrm{Al} /{ }^{27} \mathrm{Al}$ ratios, and that this range is the same as that exhibited by other CAI varieties, means that all CV CAI types - including FoBs - were initially formed at the same time and then re-melted over the same 200,000 year nebular time span (strict confirmation of this will require bulk Mg isotopic compositions be measured for FoBs to show they lie along the same whole-CAI isochron as do other CAIs)).. There is no timeevolution relationship between, e.g., highly refractory Type A CAIs and the much less-refractory 
FoBs. The essential bulk composition differences between (at least) the CAI varieties in CV3 chondrites were established simultaneously and very early in the solar nebula. There is no condensation-based temporal evolution of these CAI types.

One other interesting observation emerges from our data. As emphasized and documented by Bullock et al. (2012), one of the hallmarks of many FoBs is their clear evidence for surface melt evaporation. The result was CAI mantle bulk compositions and mineralogy that are far more aluminous than those of the CAI cores, so much so that the two mineral assemblages are out of chemical equilibrium. In extreme cases like TS35-F1 and 3137-2, the mantles are rich in anorthite and aluminous melilite but olivine free, whereas the cores contain abundant olivine and Mg-rich melilite. CAIs, like chondrules, likely experienced multiple episodes of melting and remelting. Indeed, if all CV3 CAI precursors formed contemporaneously as the data of Jacobsen et al. (2008) and Larsen et al. (2011) indicate they did, then the spread in CAI $\left({ }^{26} \mathrm{Al} /{ }^{27} \mathrm{Al}\right)_{0}$ ratios virtually mandates such multiple melting episodes. This naturally raises the possibility that the outer mantles of some FoBs might record a later melting event than that recorded by the cores. Isotopically, such a signature would be most recognizable in high $\mathrm{Al} / \mathrm{Mg}$ phases in the mantle. Anorthite unfortunately is too disturbed to be of any use in this regard, but the aluminous melilite is not. In those FoBs with Al-rich melilite in their mantles - E60, E64, and TS35-F1 - that melilite is sensibly isochronous with the olivine + spinel + pyroxene $n$ the CAI cores. Thus there is no core-mantle time gap. This is less interesting than if there were such a temporal gap, but of course this need not be the case for other FoBs.

\section{Evidence for isotopic disturbance}

As noted above in the Results section, data for anorthite in every FoB we analyzed plot significantly below the isochrons defined by the other phases in each CAI (Figs. 2-4). In some CAIs, the anorthite does contain excess $\delta^{26} \mathrm{Mg}^{*}$, and in other cases contains none whatsoever within detection limits. Conversely, in some cases both spinel and Mg-rich melilite scatter above this isochron. Even when this scatter is not entirely outside of error, it is still enough to significantly affect the isochron slope calculations as also noted in the Results section. We consider these observations in combination to be indicative of partial isotopic disturbance, but 
the differing anorthite patterns just cited are suggestive of two different processes that need not be mutually exclusive.

In those cases where the anorthite does contain significant excess $\delta^{26} \mathrm{Mg}^{*}$ (e.g., SJ101, $4 N$, and E60), it is likely that local and incomplete isotopic exchange with a low $\mathrm{Al} / \mathrm{Mg}$ phase(s) has occurred. Podosek et al. (1991) illustrated the basics of this mechanism, and suggested that the most likely phase to exchange with anorthite is Mg-rich melilite. MacPherson et al. (2012) showed that anorthite also exchanges readily with spinel, provided that the spinel is not enclosed (isolated) within another phase such as pyroxene or aluminous melilite that inhibits its isotopic exchange. Regardless of whether the anorthite exchanges with spinel and/or Mg-rich melilite, the isotopic effects are very different for the two minerals because magnesium is a trace constituent in anorthite but not in melilite or spinel. Both phases undergo bulk plus isotopic magnesium exchange but, in anorthite, the elemental exchange tends to dominate because the $\mathrm{Al} / \mathrm{Mg}$ shift is more pronounced than the magnesium isotopic shift. Specifically, the anorthite loses bulk magnesium, resulting in a data shift that is mostly to the right, rather than down, on an isochron diagram. For spinel and Mg-rich melilite the situation is opposite. Magnesium is a major (stoichiometric) component of both phases, so the trace amount of elemental magnesium acquired from the anorthite has little effect on their $\mathrm{Al} / \mathrm{Mg}$ ratios. However, because anorthite has a much higher initial ratio of ${ }^{26} \mathrm{Mg} /{ }^{24} \mathrm{Mg}$ than spinel and melilite, the isotopic shift is significant and those data points mainly move upward on an isochron diagram. Note that this is somewhat different from the mechanism outlined by Podosek et al. (1991), in the sense that in their model the anorthite data moved down more than to the right on an isochron diagram.

With specific regard to our FoB data, although there is some scatter in $\delta^{26} \mathrm{Mg}^{*}$ in the spinel data in several of the CAIs, (the spinel data within each FoB are within analytical uncertainty of each other and not strictly resolved. This differs from the clear case for anorthite-spinel exchange that was documented by MacPherson et al. (2012) However, in as noted in the Results for both E60 and 3137-2, the most Mg-rich melilite points scatter to a degree that significantly affects the MSWD of the calculated isochrons. In 3137-2 in particular, two of the Mg-are not within analytical uncertainty of the other melilite points. We thus infer that anorthite-melilite exchange reasonably explains those FoBs $(S J 101,4 N$, and E60) in which the anorthite retains significant excess $\delta^{26} \mathrm{Mg}^{*}$. 
The above mechanism for anorthite exchange with another solid phase cannot by itself explain those FoBs in which there is no detectable excess $\delta^{26} \mathrm{Mg}^{*}$ in anorthite, namely E64, 3137-2, and TS35-F1. In such cases the anorthite either formed significantly later than all the other primary phases, which is difficult to explain, or else it completely exchanged magnesium isotopes with an external reservoir that was devoid of any significant radiogenic ${ }^{26} \mathrm{Mg}$. That reservoir most likely was the meteorite matrix and fluids circulating within it on the asteroid parent body. Evidence supporting this hypothesis comes from the ubiquitous presence of secondary nepheline replacing anorthite in all the FoBs we studied, including those in the reduced CV3s Leoville and Efremovka. Secondary alteration in Allende CAIs is well documented throughout the literature, but it is far less documented in the reduced CV3s. Figure 8 shows BSE images of anorthite in the inclusions 3137-2 and E60 from Vigarano and Efremovka, respectively. These objects show far less secondary mineralization than do their Allende counterparts, but the incipient replacement of anorthite by nepheline is clear. As Fig. 8 illustrates, this initial replacement characteristically takes the form of very thin lamellae of nepheline within the anorthite crystals. Finally, recall that the anorthite in most FoBs is confined to the outermost regions of the CAIs, near the contact with the meteorite matrices. If the nepheline formation is related to fluid-assisted metasomatism that occurred on the CV3 parent body, as suggested by Krot et al. (1995), it is reasonable to assume that the portions of CAIs nearest the meteorite matrix will be most affected. We conclude that fluid assisted isotopic exchange best explains the lack of any excess $\delta^{26} \mathrm{Mg}^{*}$ in anorthite in E64, 3137-2, and TS35-F1. We repeat, however, that there is no reason that the two processes described above - local exchange between solid phases $v s$. wholesale exchange with an external fluid - need be mutually exclusive. In fact, additional detailed work undoubtedly will show that both operated in parallel.

\section{Initial Mg-isotope ratios}

Based on their whole-CAI data obtained by MC-ICP-MS, B. Jacobsen et al (2008) determined initial $\delta^{26} \mathrm{Mg}^{*}=-0.040 \pm 0.029 \%$ relative to terrestrial magnesium; this value is considered to be the best estimate for the solar system initial value (Davis and McKeegan, 2014). However, relative to the latter value, $S J 101$ has initial $\delta^{26} \mathrm{Mg}^{*}$ that is unambiguously more negative, ALVIN is within error but only at the limit of both error sets, and E64 is unambiguously more positive. Despite the apparent scatter in some of the olivine data, the precision of our 
determined values for initial $\delta^{26} \mathrm{Mg}^{*}$ is comparable to that of Jacobsen et al. (2008), mostly $\pm 0.03-0.05 \%$. These values are largely constrained by forsterite, which plots very close to the intercept, yet our forsterite data for all seven FoBs do not converge on or cluster close to the solar system initial ratio of Jacobsen et al. (2008). Recall also that all analyses for each phase were done within a single run, meaning that all olivines in all our samples collectively were analyzed in a single day. Thus these isotopic differences are real and not an analytical artifact. The only systematic correlation that is apparent from our data is that the two most primitive FoBs, SJ101 and ALVIN, are the ones with the most negative initial $\delta^{26} \mathrm{Mg}^{*}$.

Higher initial $\delta^{26} \mathrm{Mg}$ * can be due to later remelting and simple ${ }^{26} \mathrm{Mg}$ evolution with time due to ${ }^{26} \mathrm{Al}$ decay, but more negative values cannot be explained in this manner. Despite the apparent differences between our data and the whole-CAI results of Jacobsen et al. (2008) and Larsen et al. (2011), there is no reason to view our results as discrepant in any way. To the contrary, we are not the first to observe large negative values for initial $\delta^{26} \mathrm{Mg} *$. Wasserburg et al. (2012), analyzed one CAI with very high precision and obtained initial $\delta^{26} \mathrm{Mg}^{*}=-0.127 \pm 0.032$. This same CAI has a nearly canonical initial ${ }^{26} \mathrm{Al} /{ }^{27} \mathrm{Al}$ ratio, $(5.27 \pm 0.18) \times 10^{-5}$. Wasserburg et al. (2012) suggested that widespread isotopic heterogeneity existed for many elements in the early solar nebula. Even larger negative initial $\delta^{26} \mathrm{Mg}^{*}$ values were previously measured in some ("PLAC") hibonites from CM chondrites (Liu et al., 2012; Kööp et al., 2016). Some degree of heterogeneity in initial $\delta^{26} \mathrm{Mg} *$ must have existed at an early stage of solar system history.

\section{Mass-dependent isotopic fractionation and the evolution of FoBs}

Although we did not undertake as detailed or precise of a study of mass-dependent fractionation in these FoBs as Bullock et al. (2013) did for Type B CAIs, nonetheless some interesting observations emerge within the context of FoB evolution model presented by Bullock et al. (2012).

One surprising result is the wide range of $\delta^{25} \mathrm{Mg}$ between the seven FoBs. SJ101 and ALVIN have $\delta^{25} \mathrm{Mg}$ close to $0 \%$ in bulk except for spinel, whereas for example every phase in 3137-2 has positive $\delta^{25} \mathrm{Mg}=6-8 \%$. Given the fact (noted previously) that each phase from all CAIs was analyzed in the same run, these inter-CAI differences in $\delta^{25} \mathrm{Mg}$ are real. 
The expectation from the Bullock et al. (2012) model is that the mantles of those FoBs showing evidence for the most extreme melt evaporation should also show the highest positive values of $\delta^{25} \mathrm{Mg}$. The results are decidedly mixed. TS35-F1 represents the most extreme case for melt evaporation, and in fact the pattern of enrichment illustrated $n$ Fig. 6 supports this interpretation remarkably well. Ignoring the anorthite $\delta^{25} \mathrm{Mg}$, which is suspect (in this and all of the FoBs) owing to isotopic disturbance, the aluminous melilite in the outer mantle is significantly enriched relative to all other phases excepting for one spinel point (which also is in the mantle). This is consistent with the melilite (and some spinel) having crystallized from mantle melt that had experienced magnesium loss due to evaporation. This result also implies that melting and solidification were too rapid for the mantle and core to equilibrate. At the other extreme, the least evaporated FoBs (SJ101, ALVIN, and 4N) show little petrologic evidence for significant magnesium loss in their mantles and there no evidence anywhere for enhanced or even positive $\delta^{25} \mathrm{Mg}$ in any of the phases except spinel, which is enriched even in the CAI core and therefore is unlikely due to melt evaporation at the CAI surface. Thus SJ101, ALVIN, and $4 N$ are isotopically consistent with the Bullock et al. (2012) model. The other FoBs do not conform to a single isotopic pattern. For example, all phases in all parts of $3137-2$ have high $\delta^{25} \mathrm{Mg}$, with melilite and spinel being slightly more enriched than pyroxene and olivine. As this inclusion is one of those postulated by Bullock et al. (2012) to have experienced the greatest degree of melt evaporation, the observed isotopic systematics imply either that the CAI was originally enriched in ${ }^{25} \mathrm{Mg}$ and melt evaporation had no discernable isotopic effect, or else that the melt equilibrated internally after evaporation but prior to solidification. Both E60 and E64 are internally very heterogeneous with respect to $\delta^{25} \mathrm{Mg}$, but in an unexpected way. The aluminous melilite in the outer mantles of the CAIs is the least ${ }^{25} \mathrm{Mg}$-rich phase in the CAIs, contrary to a expectations of a simple melt evaporation model (Bullock et al., 2012). However, this pattern also has been observed in some Type B CAIs (Bullock et al., 2013) that also show evidence of surface melt evaporation, Given the indisputable fact that the aluminous melilite in the outer mantles of these FoBs is not in equilibrium with the interior $\mathrm{Mg}$-rich melilite, we remain convinced that surface melt evaporation of magnesium did occur. Thus the only explanation for the isotopic data is isotopic re-equilibration of the mantle with an exterior isotopic reservoir, namely the surrounding gas at the time of melt evaporation. Why such re-equilibration did not occur in the case of TS35$F 1$ is a mystery. 


\section{SUMMARY}

High-precision SIMS Al-Mg isotope measurements of minerals in seven FoBs yield internal isochrons with a range of inferred initial ${ }^{26} \mathrm{Al} /{ }^{27} \mathrm{Al}$, from $5.30 \times 10^{-5}$ to $4.17 \times 10^{-5}$. This range corresponds to an extended time interval, on the order of 200,000 years, over which the different CAIs were re-melted from their precursors. As this range matches that among other types of coarse-grained igneous CAIs from CV chondrites, the large differences in bulk composition between FoBs and those other CAI varieties is not a function of condensation controlled temporal evolution. In fact the most primitive $\mathrm{FoB}, S J 101$, has $\left({ }^{26} \mathrm{Al} /{ }^{27} \mathrm{Al}\right)_{0}$ of $(5.24 \pm 0.52) \times 10^{-5}$, indistinguishable from the best estimate for the solar system initial value determined by Jacobsen et al. (2008). Thus, the wide range of CAI bulk compositions was established simultaneously and early. Also, there is no correlation between the degree of melt evaporation of a given FoB and its initial ${ }^{26} \mathrm{Al} /{ }^{27} \mathrm{Al}$ ratio: some highly melt-evaporated FoBs were melted very early, while some primitive FoBs underwent much later melting. The initial $\delta^{26} \mathrm{Mg}^{*}$ value (relative to terrestrial magnesium) in the most primitive FoB (SJ101) is significantly lower than the canonical solar system value of $-0.040 \pm 0.029 \%$.

In all the FoBs we analyzed, anorthite data consistently fall below the isochrons defined by coexisting phases with lower $\mathrm{Al} / \mathrm{Mg}$. Two different processes likely are responsible for this isotopic disturbance: local exchange between anorthite and magnesium-rich melilite, and exchange with an external fluid on the asteroid parent body, possibly the same one responsible for sodium metasomatism and the formation of nepheline.

\section{ACKNOWLEDGEMENTS}

We gratefully acknowledge Andy Davis, Associate Editor Dimitri Papanastassiou, and an anonymous reviewer for very helpful reviews that significantly improved this paper. This research was supported by National Aeronautics and Space Administration (NASA) grants NNX11AD43G and NNX15AH68G (GJM, PI), NNX10AH76G and 14-EW14-2-0049 (ANK, PI), NNX08AH79G (MP, PI), NNX11AK82G and NNX15AH66G (SBJ, PI), and NNX09AB88G (NK, PI). WiscSIMS is partly supported by National Science Foundation grants EAR03-19230 and EAR07-44079. 


\section{REFERENCES}

Amelin Y., Krot A. N., Hutcheon I. D., and Ulyanov A. A. (2002) Lead isotopic ages of chondrules and calcium-aluminum-rich inclusions. Science 297, 1678-1683.

Bullock E. S., MacPherson G. J. Nagashima K., Krot A. N., Petaev M. I., Jacobsen S. B., and Ulyanov A. A. (2012) Forsterite-bearing type B refractory inclusions from CV3 chondrites: From aggregates to volatilized melt droplets. Meteorit. Planet. Sci. 47, $2128-2147$.

Bullock E. S., Knight K. B., Richter F. M., Kita N. T., Ushikubo T., Davis A. M., MacPherson G. J., Mendybaev R. A. (2013) Evaporation conditions inferred from Mg and Si isotopic fractionation in melilite from Type B1 and B2 CAIs. MAPS 48, 1440-1458.

Bullock E. S., Nakashima D., Tenner T. J., Kita N. T., MacPherson G. J., Ivanova M. A., Krot A. N., Petaev M. I., Jacobsen S. B. (2014) High-precision Al-Mg systematics in forsteritebearing Type B CAIs (abstract) Goldschmidt Conference, Sacramento CA.

Bullock E. S., Tenner T. J., Nakashima D., Kita N. T., MacPherson G. J., Ivanova M. A., Krot A. N., Petaev M. I., and Jacobsen S. B. (2015). High precision Al-Mg systematics of forsterite-bearing Type B CAIs (abstract). Lunar Planet. Sci. 46, \#1971.

Clayton R. N., MacPherson G. J., Hutcheon I. D., Davis A. M., Grossman L., Mayeda T. K., Molini-Velsko C., Allen J. M., and El Goresy A. (1984) Two forsterite-bearing FUN inclusions in the Allende meteorite. Geochim. Cosmochim. Acta 48, 533-548.

Davis A. M., Hinton R. W., and MacPherson G. J. (1987) Relict grains in a Vigarano refractory inclusion. Meteoritics 22, 363-365 (abstr.).

Davis A. M. and McKeegan K. D. (2014) Short-lived radionuclides and early solar system chronology. In Meteorites and Cosmochemical Processes (Ed. A. M. Davis), Vol. 1 Treatise on Geochemistry, 2nd Ed. (Exec. Eds. H. D. Holland and K. K. Turekian), Elsevier, Oxford, pp. 361-395.

Davis A. M., Richter F. M., Mendybaev R. A., Janney P. E., Wadhwa M., and McKeegan K. D. (2015) Isotopic mass fractionation laws for magnesium and their effects on ${ }^{26} \mathrm{Al}-{ }^{26} \mathrm{Mg}$ systematics in solar system materials. Geochim. Cosmochim. Acta 158, 245-261. 
Grossman L. (1972) Condensation in the primitive solar nebula. Geochim. Cosmochim. Acta 36, 597-619.

Ireland TR (1988) Correlated morphological, chemical, and isotopic characteristics of hibonites from the Murchison carbonaceous chondrite. Geochim. Cosmochim. Acta 52, 2827-2839.

Ivanova M. A., Nagashima K., Krot A. N., and MacPherson G. J. (2012) Calcium-aluminum-rich inclusions with relict ultra-refractory inclusions rich in $\mathrm{Zr}, \mathrm{Y}$, and $\mathrm{Sc}$ from Efremovka and North West Africa 3118 CV3 carbonaceous chondrites: Evidence for multistage formation in oxygen isotopic reservoirs of variable composition. Meteorit. Planet. Sci. 47, 2107-2127.

Ivanova M. A., Park C., Lorenz C. A., Krot A. N., Bullock E. S., Nakashima D., Tenner T. J, Kita N. T., and MacPherson G. J. (2014) Plastically deformed forsterite-bearing Type B CAI from NWA 3118 (CV3) (abstract). Lunar Planet. Sci. 45, \#5213.

Jacobsen B., Yin Q.-Z, Moynier F., Amelin Y., Krot A. N., Nagashima K., Hutcheon I. D., and Palme H. (2008) ${ }^{26} \mathrm{Al}-{ }^{26} \mathrm{Mg}$ and ${ }^{207} \mathrm{~Pb}-{ }^{206} \mathrm{~Pb}$ systematics of Allende CAIs: Canonical solar initial ${ }^{26} \mathrm{Al} /{ }^{27} \mathrm{Al}$ ratio reinstated. Earth Planet. Sci. Lett. 272, 353-364.

Jacobsen S. B., Chakrabarti R., Ranen M.C. and Petaev M. I. (2008) High resolution ${ }^{26} \mathrm{Al}-{ }^{26} \mathrm{Mg}$ chronometry of CAIs from the Allende meteorite (abstract). Lunar Planet. Sci. 39, \#1999.

Kita N. T., Ushikubo T., Knight K. B., Mendybaev R. A., Davis A. M., Richter F. M., and Fournelle J. H (2012) Internal ${ }^{26} \mathrm{Al}-{ }^{26} \mathrm{Mg}$ isotope systematics of a Type B CAI: Remelting of refractory precursor solids. Geochim. Cosmochim. Acta 86, 37-51.

Kita N. T. and Ushikubo T. (2012) Evolution of protoplanetary disk inferred from ${ }^{26} \mathrm{Al}$ chronology of individual chondrules. Meteorit. Planet. Sci. 47, 1108-1119.

Kita N. T., Yin Q.-Z., MacPherson G. J., Ushikubo T., Jacobsen B., Nagashima K., Kurahashi E., Krot A. N., and Jacobsen S. B. (2013) Al-Mg isotope systematics of the first solids in the early solar system. Meteorit. Planet. Sci. 48, 1383-1400.

Kööp L., Davis A. M., Nakashima D., Park C., Krot A. N., Nagashima K., Tenner T. J., Heck P. R., and Kita N. T. (2016) A link between oxygen, calcium and titanium isotopes in ${ }^{26} \mathrm{Al}$ - 
depleted hibonite-rich CAIs from Murchison and implications for the heterogeneity of dust reservoirs in the solar nebula. Geochim. Cosmochim. Acta 189, 70-95.

Krot A. N., McKeegan K. D., Russell S. S., Meibom A., Weisberg M. K., Zipfel J., Krot T. V., Fagan T. J., and Keil K. (2001) Refractory Ca, Al-rich inclusions and Al diopside-rich chondrules in the metal-rich chondrites Hammadah al Hamra 237 and QUE 94411. Meteorit. Planet. Sci. 36, 1189-1217.

Krot A. N., Amelin Y., Bland P., Ciesla F. J., Connelly J., Davis A. M., Huss G. R., Hutcheon I. D., Makide K., Nagashima K., Nyquist L. E., Russell S. S., Scott E. R. D., Thrane K., Yurimoto H., and Yin Q.-Z. (2009) Origin and chronology of chondritic components: A review. Geochim. Cosmochim. Acta 73, 4963-4998.

Krot A. N., Makide K., Nagashima K., Huss G. R., Ogliore R. C., Ciesla F. J., Yang L., Hellebrand E., and Gaidos E. (2012) Heterogeneous distribution of ${ }^{26} \mathrm{Al}$ at the birth of the solar system: evidence from refractory grains and inclusions. Meteorit. Planet. Sci. 47, $1948-1979$.

Krot A. N., Nagashima K., Wasserburg G. J., Huss G. R., Papanastassiou D., Davis A. M., Hutcheon I. D., and Bizzarro M. (2014) Calcium-aluminum-rich inclusions with fractionation and unknown nuclear effects (FUN CAIs): I. Mineralogy, petrology, and oxygen-isotope compositions. Geochim. Cosmochim. Acta 145, 206-247.

Larsen K., Trinquier A., Paton C., Schiller M., Wielandt D., Ivanova M., Connelly J., Nordlund A., Krot A. N., and Bizzarro M. (2011) Evidence for magnesium-isotope heterogeneity in the solar protoplanetary disk. Astrophys. J. 735, L37-L40.

Liu M.-C., Chaussidon M., Göpel C., and Lee T. (2012) A heterogeneous solar nebula as sampled by CM hibonite grains. Earth Planet. Sci. Letters 327, 75-83.

MacPherson G. J. and Davis A. M. (1992) Evolution of a Vigarano forsterite-bearing CAI. Meteoritics 27, 253.

MacPherson G. J. and Huss G. R. (2005) Petrogenesis of Al-rich chondrules: Evidence from bulk compositions and phase equilibria. Geochim. Cosmochim. Acta 69, 3099-3127. 
MacPherson G. J., Bullock E. S., Janney P. E., Kita N., Ushikubo T., Davis A. M., Wadhwa M., and Krot A. N. (2010) Early solar nebula condensates with canonical, not supracanonical, initial ${ }^{26} \mathrm{Al} /{ }^{27} \mathrm{Al}$ ratios. Astrophys. J. Lett. 711, L117-L121.

MacPherson G. J., Kita N. T., Ushikubo T., Bullock E. S., and Davis A. M. (2012) Well-resolved variations in the formation ages for Ca-Al-rich inclusions in the early Solar System Earth Planet. Sci. Lett. 331, 43-54.

Petaev M. I. and Jacobsen S. B. (2009) SJ101, a new forsterite-bearing CAI from the Allende CV3 chondrite: SEM and EPMA studies. Geochimica Cosmochim. Acta. 73, 5100-5114.

Podosek F. A., Zinner E. K., MacPherson G. J., Lundberg L., Brannon J. C., and Fahey A. F. (1991) Correlated study of initial ${ }^{87} \mathrm{Sr} /{ }^{86} \mathrm{Sr}$ and $\mathrm{Al}-\mathrm{Mg}$ isotopic systematics and petrologic properties in a suite of refractory inclusions from the Allende meteorite. Geochim. Cosmochim. Acta 55, 1083-1110.

Ushikubo T., Kimura M., Kita N. T., and Valley J. W. (2012) Primordial oxygen isotope reservoirs of the solar nebula recorded in chondrules in Acfer 094 carbonaceous chondrite. Geochim. Cosmochim. Acta 90, 242-264

Wadhwa M., Janney P. E., and Krot A. N. (2009) Al-Mg isotope systematics in the Efremovka E60 CAI: Evidence of re-equilibration (abstract). Meteorit. Planet. Sci. Supplement, p.5431.

Wark D. A., Boynton W. V., Keays R. R., and Palme H. (1987) Trace element and petrologic clues to the formation of forsterite-bearing Ca-Al-rich inclusions in the Allende meteorite. Geochim. Cosmochim. Acta 51, 607-622.

Wasserburg G. J., Lee T, and Papanastassiou D. A. (1977) Correlated O and Mg isotopic anomalies in Allende inclusions: II. Magnesium. Geophysical Research Letters 4, 299302.

Wasserburg G. J., Wimpenny J., and Yin Q.-Z. (2012) Mg isotopic heterogeneity, Al-Mg isochrons, and canonical ${ }^{26} \mathrm{Al} /{ }^{27} \mathrm{Al}$ in the early solar system. Meteorit. Planet. Sci. 47, 1980-1997.

Yoneda S. and Grossman L. (1995) Condensation of CaO-MgO- $\mathrm{Al}_{2} \mathrm{O}_{3}-\mathrm{SiO}_{2}$ liquids from cosmic gases. Geochim. Cosmochim. Acta 59, 3413-3444. 
Table 1. Summary of initial $\left({ }^{26} \mathrm{Al} /{ }^{27} \mathrm{Al}\right)_{0}$ and $\delta^{26} \mathrm{Mg} *_{0}$ for each FoB.

\begin{tabular}{|c|c|c|c|c|}
\hline $\mathbf{C A I}$ & $\left(^{\mathbf{2 6}} \mathbf{A l} \mathbf{~}^{\mathbf{2 7}} \mathbf{A l}\right)_{\mathbf{0}}$ & $\mathbf{2} \boldsymbol{\sigma}$ & $\mathbf{\delta}^{\mathbf{2 6}} \mathbf{M g} *_{\mathbf{0}}$ & $\mathbf{2} \boldsymbol{\sigma}$ \\
\hline $\begin{array}{c}\text { Solar System }_{\text {Initial }^{a}}{ }^{2} \\
\text { SJ101 }\end{array}$ & $5.23 \times 10^{-5}$ & 0.13 & -0.040 & 0.029 \\
\hline ALVIN & $4.17 \times 10^{-5}$ & 0.53 & -0.128 & 0.037 \\
\hline $4 \mathrm{~N}$ & $4.70 \times 10^{-5}$ & 0.43 & -0.092 & 0.029 \\
\hline E64 & $5.20 \times 10^{-5}$ & 0.35 & -0.005 & 0.027 \\
\hline E60 & $5.30 \times 10^{-5}$ & 0.22 & -0.081 & 0.030 \\
\hline V3137 & $4.76 \times 10^{-5}$ & 0.35 & -0.007 & 0.038 \\
\hline TS35 & $4.69 \times 10^{-5}$ & 0.28 & -0.070 & 0.031 \\
\hline
\end{tabular}

${ }^{\mathrm{a}}$ From Jacobsen et al. (2008). 

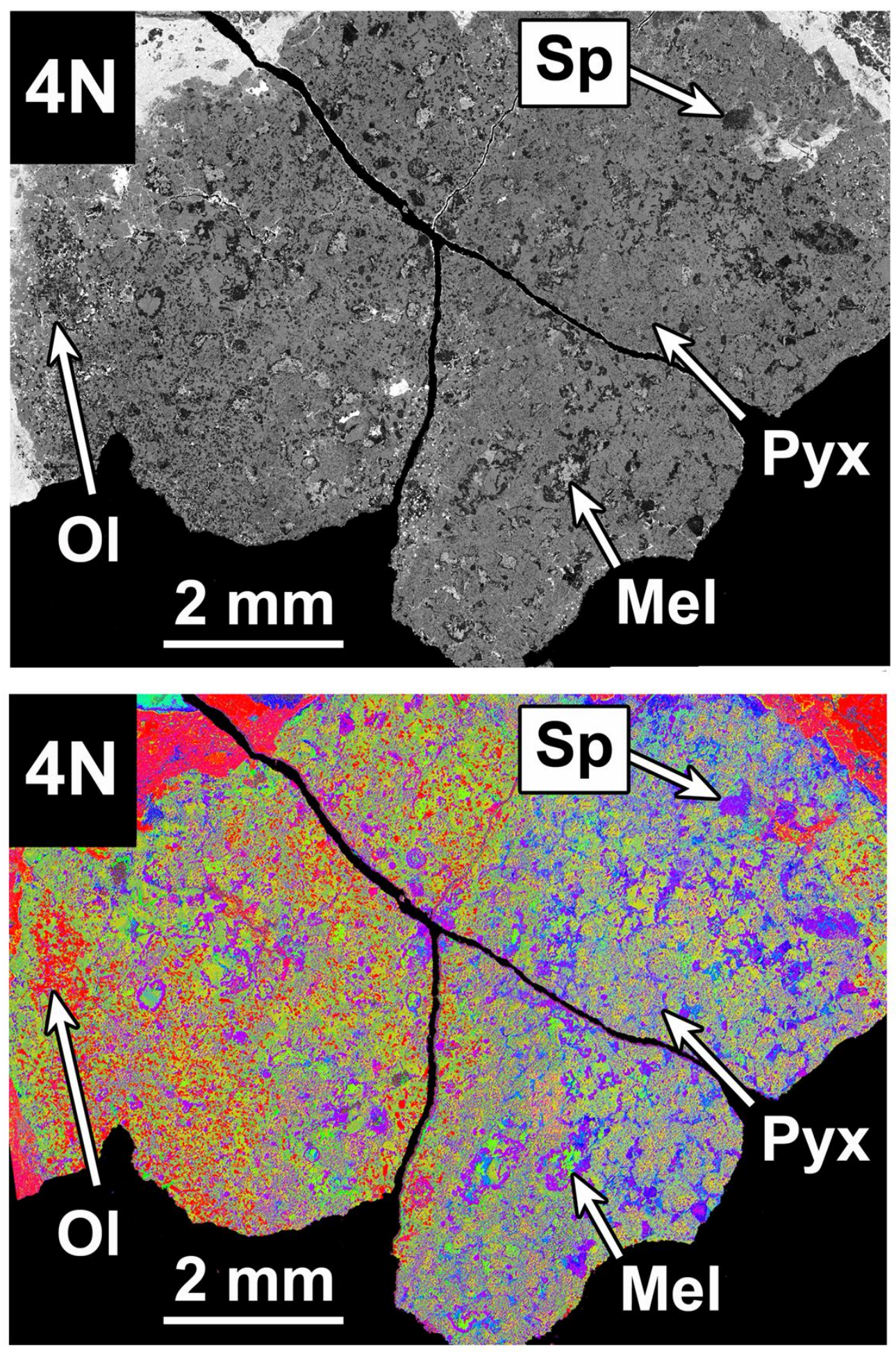

Figure 1. BSE image (top) and Ca-Al-Mg element map (bottom) of the inclusion NWA-3118 $4 N$. In the lower image, calcium is green, magnesium is red, and aluminum is blue. Abbreviations: Mel - melilite, light green; Ol - olivine, red; Pyx - pyroxene, light orange to olive green; Sp spinel, maroon. Not labelled are anorthite (sky blue) and feldspathoids (dark blue) 

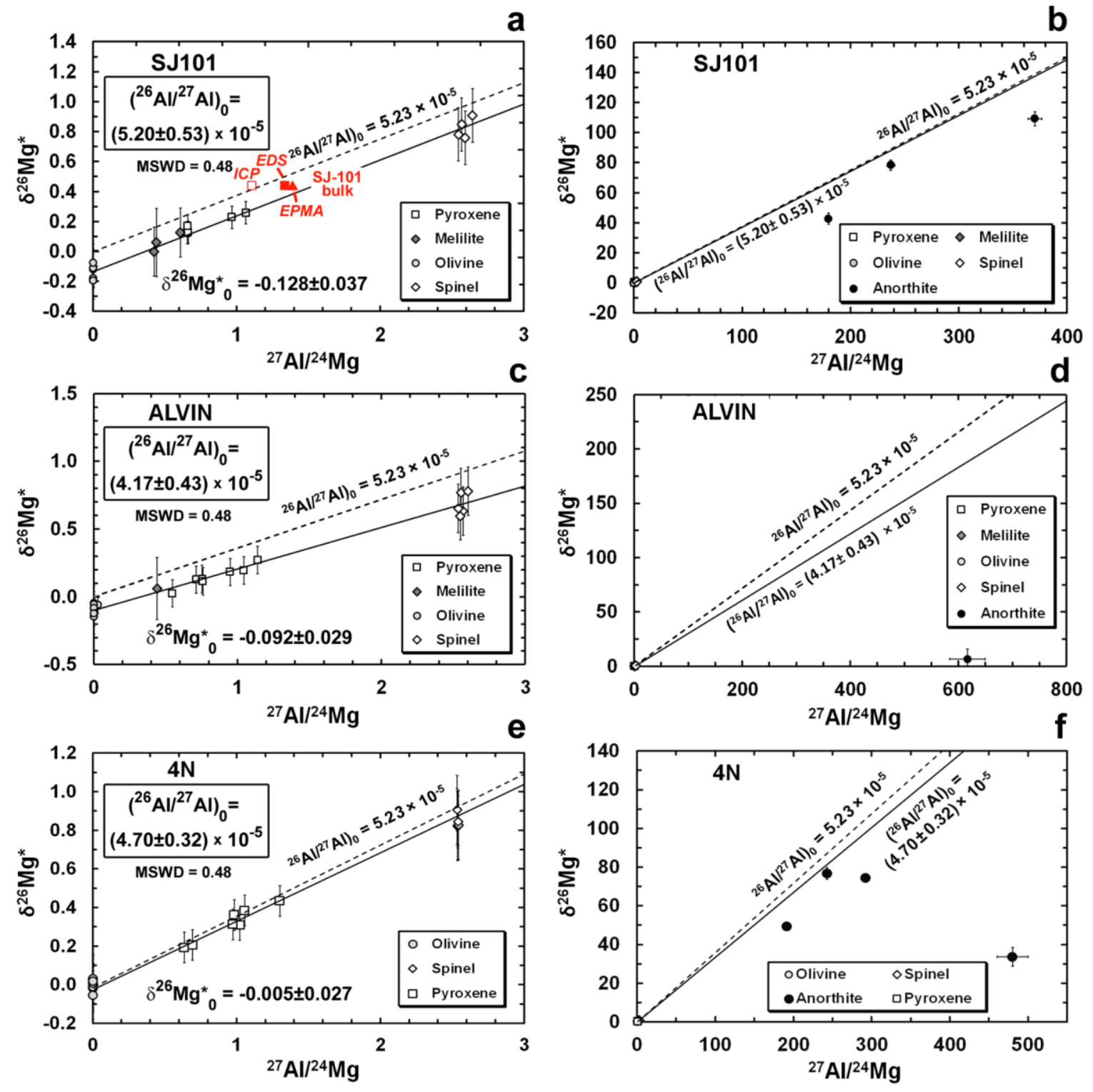

Figure 2. Al-Mg isochron diagrams for the least reprocessed FoB CAIs, SJ101, ALVIN, and 4N. All error bars are $2 \sigma$; where not visible, error bars are smaller than the plotting symbol. The red symbols in (a) show three determinations of the bulk ${ }^{27} \mathrm{Al} /{ }^{24} \mathrm{Mg}$ composition of SJ101, as determined by inductively-coupled-plasma mass-spectrometry (ICP-MS; S. B. Jacobsen et al., 2009), by EDS spectral imaging (EDS; our data), and electron microprobe area analysis (EPMA; Petaev and Jacobsen, 2009). In this figure as well as Figures 3 and 4, diagrams on left side show data for low $\mathrm{Al} / \mathrm{Mg}$ phases, and diagrams on the right side show data for anorthite. On the anorthite diagrams, the solid lines are extrapolations of the isochrons defined by the low $\mathrm{Al} / \mathrm{Mg}$ phases in each object. The dashed lines here and on Figures 3 and 4 are reference lines having slope $5.23 \times 10^{-5}$, assumed to be the initial solar system value (Jacobsen et al., 2008). 
a
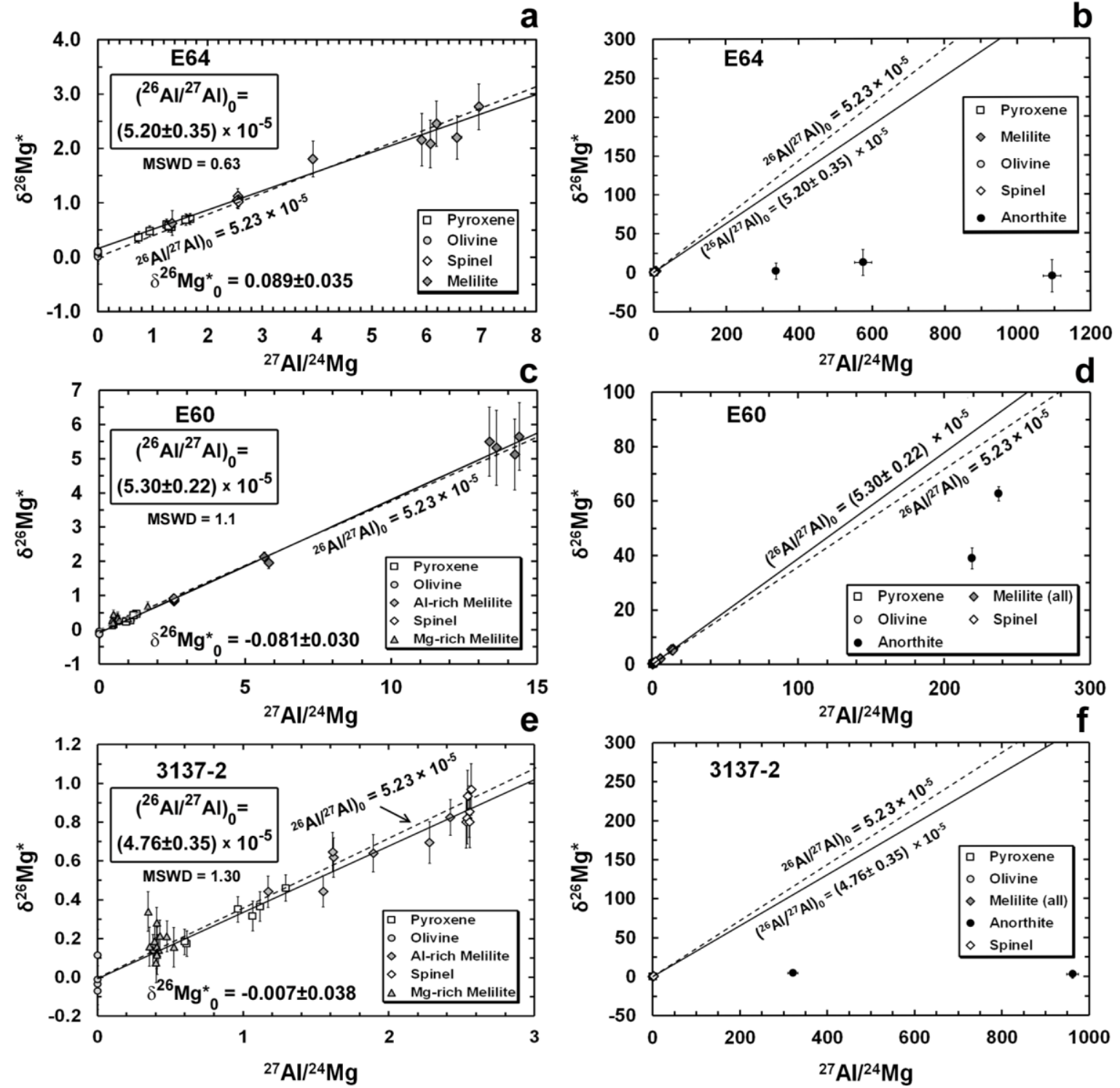

Figure 3. Al-Mg isochron diagrams for the moderately reprocessed FoB CAIs, E64, E60, and 3137-2. All error bars are $2 \sigma$; where not visible, error bars are smaller than the plotting symbol. The date for $\mathrm{Mg}$-rich melilite are shown (filled triangles) but were excluded from the regression, as explained in the text. Other features as in Fig. 2. 

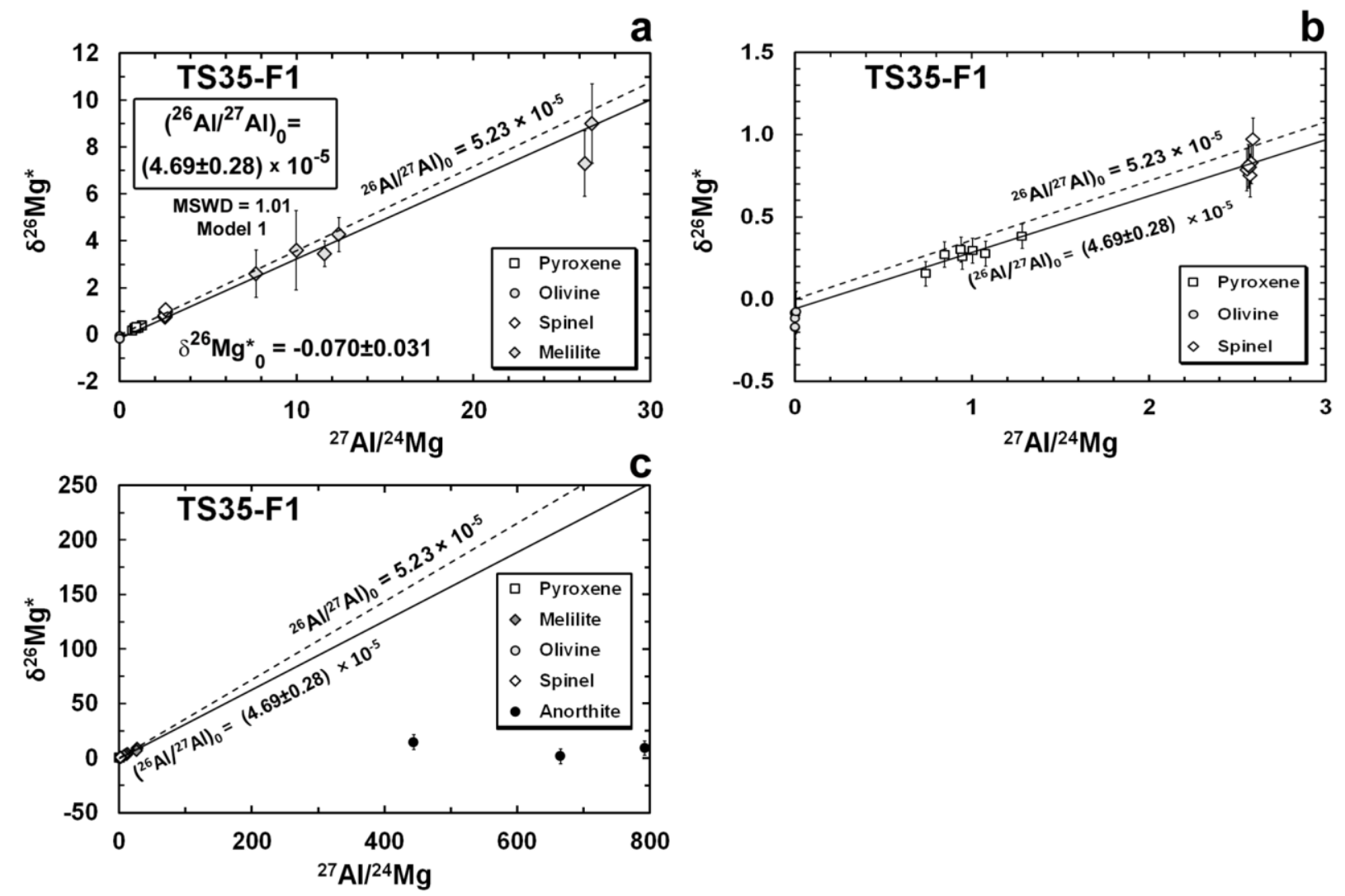

Figure 4. Al-Mg isochron diagrams for the highly reprocessed FoB CAI TS35-F1. All error bars are $2 \sigma$; where not visible, error bars are smaller than the plotting symbol. Other features as in Fig. 2. 

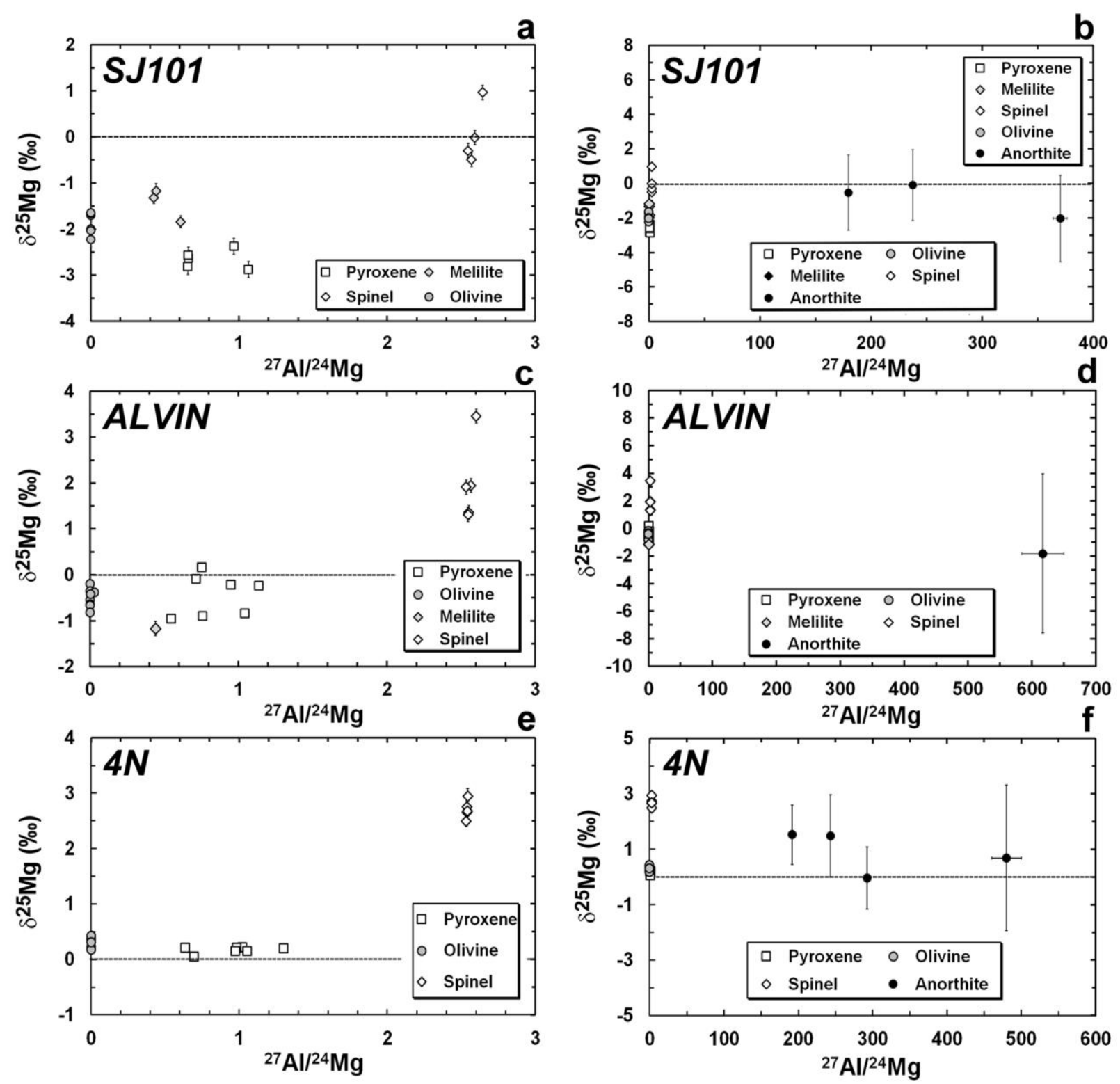

Figure 5. Mass-dependent fractionation diagrams $\left(\delta^{25} \mathrm{Mg}\right.$ vs. $\left.{ }^{27} \mathrm{Al} /{ }^{24} \mathrm{Mg}\right)$ for $S J 101, A L V I N$, and $4 N$. All error bars are $2 \sigma$; where not visible, error bars are smaller than the plotting symbol. 
a
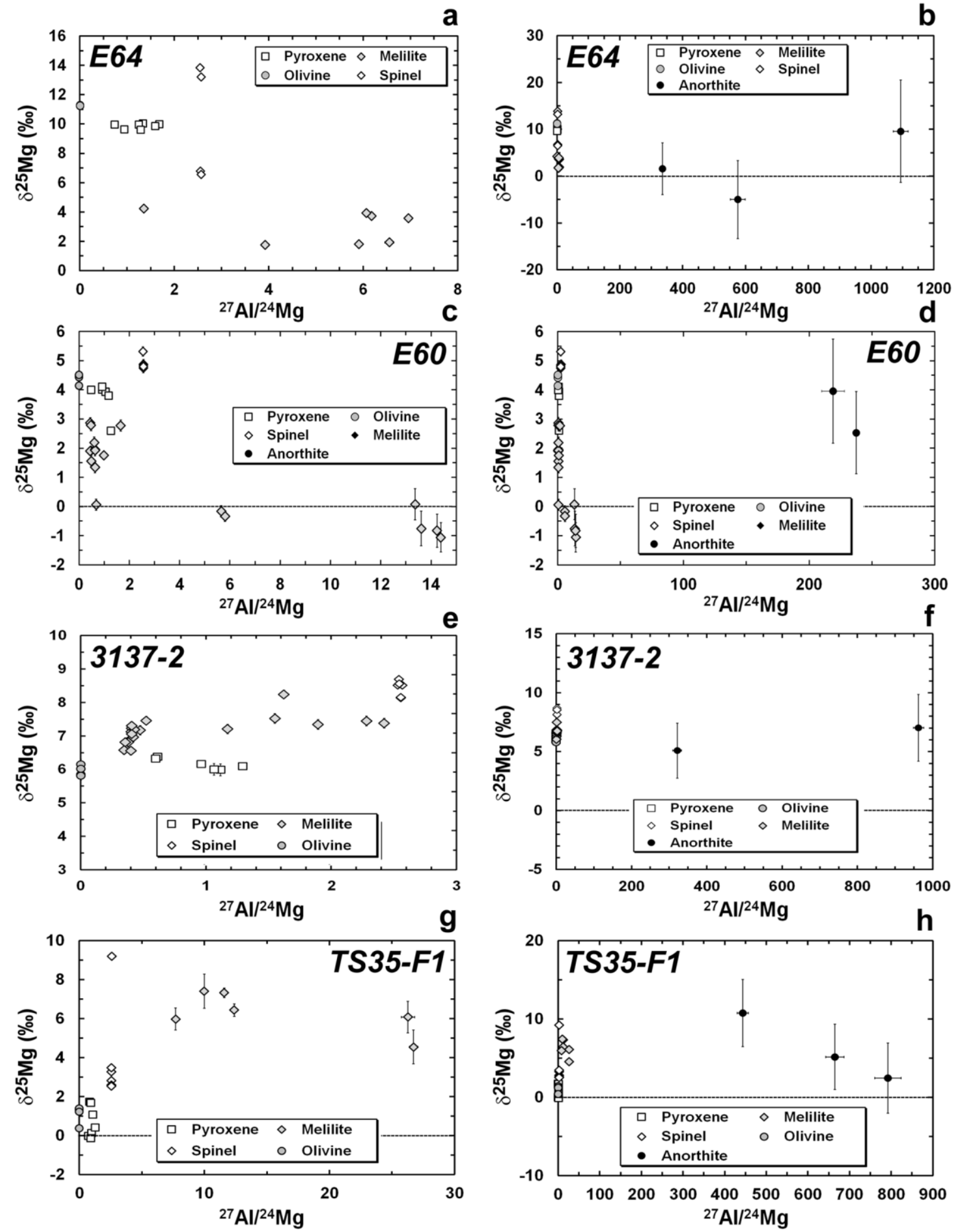

Figure 6. Mass-dependent fractionation diagrams $\left(\delta^{25} \mathrm{Mg} v \mathrm{vs} .{ }^{27} \mathrm{Al} /{ }^{24} \mathrm{Mg}\right)$ for $E 64, E 60,3137-2$, and TS35-F1. All error bars are $2 \sigma$; where not visible, error bars are smaller than the plotting symbol. 


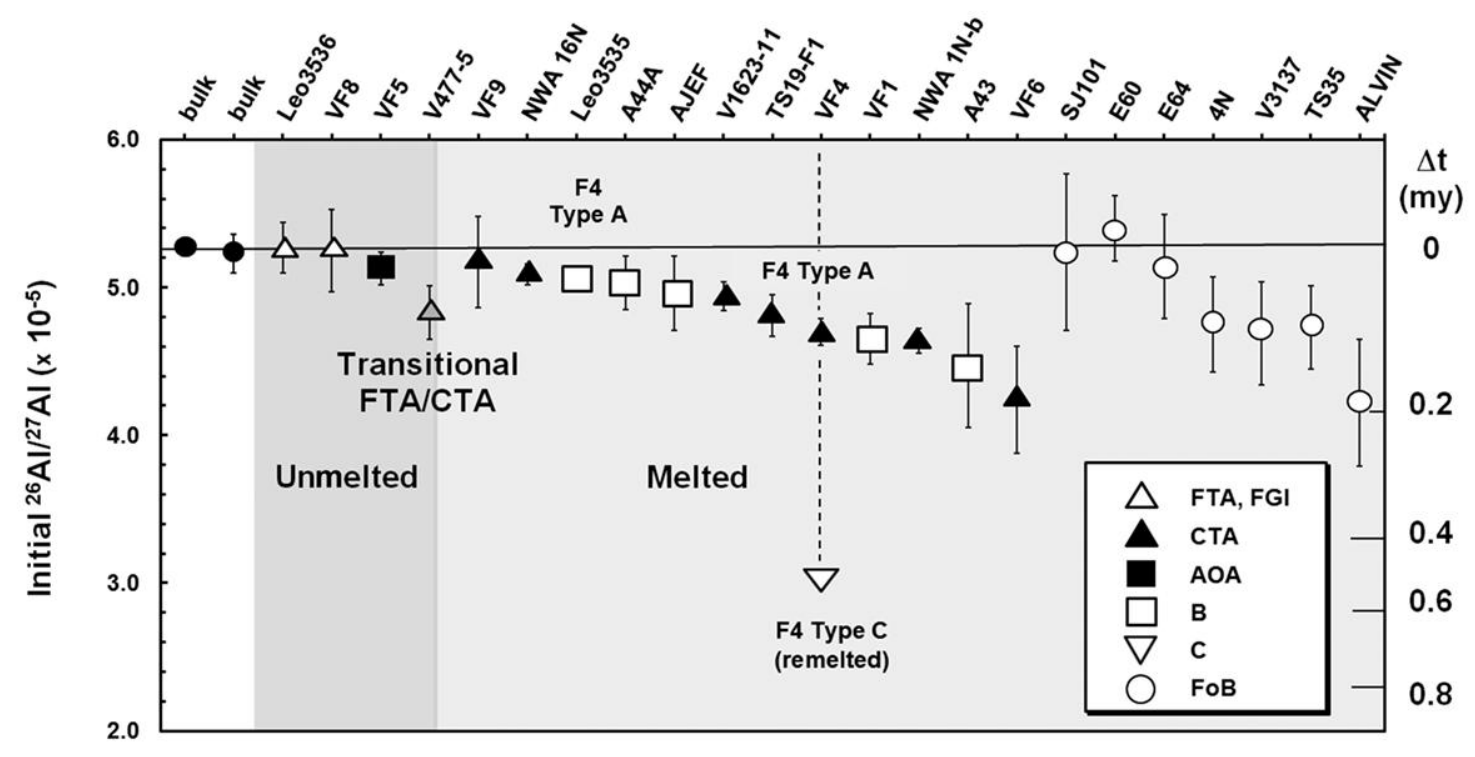

Figure7. High-precision initial ${ }^{26} \mathrm{Al} /{ }^{27} \mathrm{Al}$ ratios in $\mathrm{CAI}$ s from $\mathrm{CV} 3$ chondrites. Inclusions that are interpreted as unmelted are Fluffy Type A (FTA), amoeboid olivine aggregates (AOA) and finegrained spinel-rich inclusions (FGI), All of these consistently show $\left({ }^{26} \mathrm{Al} /{ }^{27} \mathrm{Al}\right)_{0}$ of $5.2 \times 10^{-5}$, with the exception of $V 477-5$, which was re-heated but not melted, resetting it's $\mathrm{Al} / \mathrm{Mg}$ systematics (e.g. see Davis et al., 1987). Inclusions that show petrographic evidence for having been melted (Compact Type A, or CTA; Type B and Type C CAIs) all have $\left({ }^{26} \mathrm{Al} /{ }^{27} \mathrm{Al}\right)_{0}<5.2 \times 10^{-5}$. The FoBs show the same range in $\left({ }^{26} \mathrm{Al} /{ }^{27} \mathrm{Al}\right)_{0}$ as do other CAIs from $\mathrm{CV} 3$ chondrites, corresponding to melting and recrystallizing over a 200,000 year time period. FoB data - this work; other data MacPherson et al. (2010, 2012), Kita et al. (2012). 

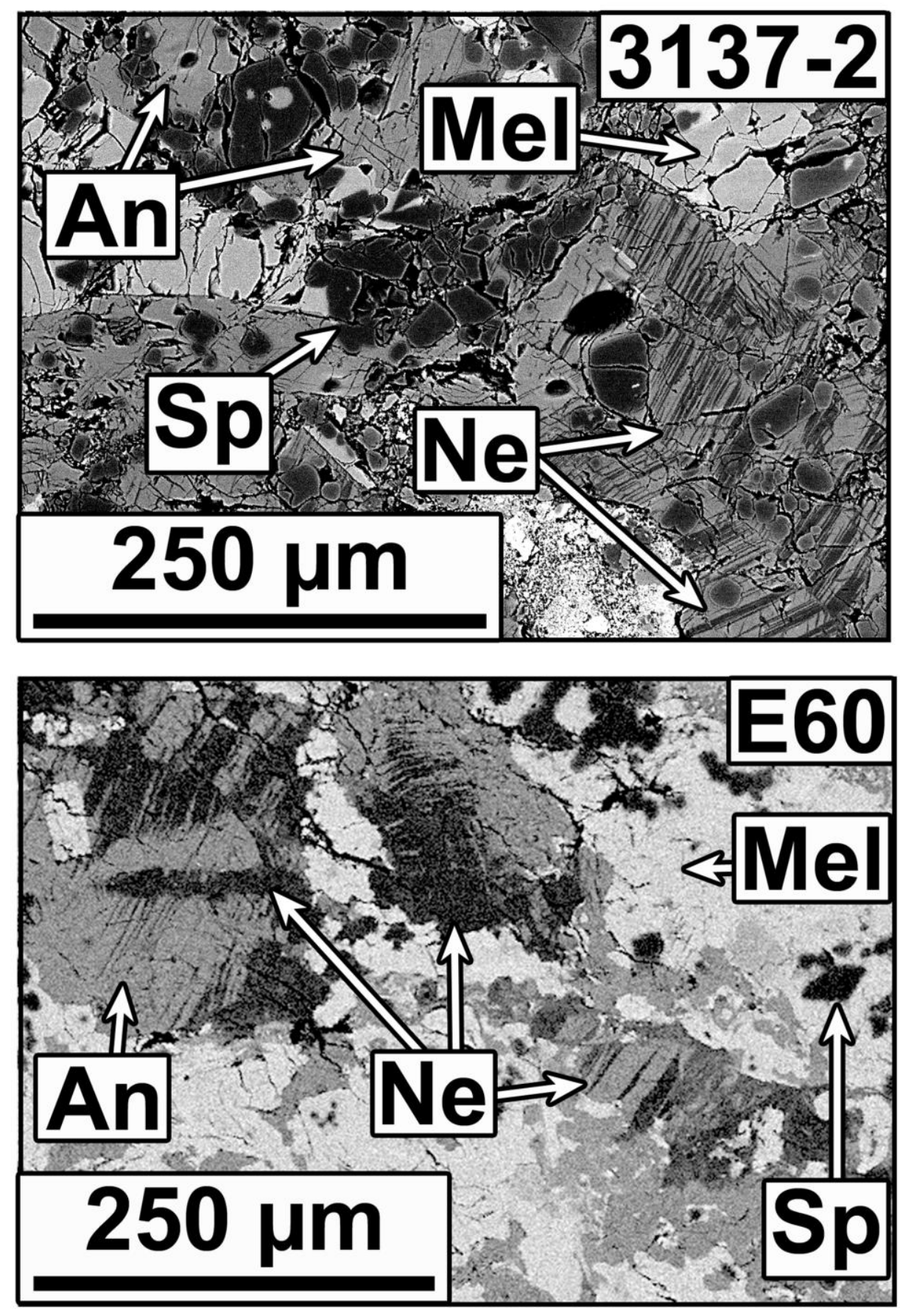

Figure 8. BSE images of anorthite (An) being partially replaced by nepheline (Ne) in Vigarano 3137-2 (top) and Efremovka E60 (bottom). Note that the nepheline starts off as dark parallel lamellae within the anorthite, which locally merge to form dark masses. Other abbreviations: Mel: melilite; Sp: spinel. 
APPENDIX A

Table A1. Al-Mg isotopic data.

\begin{tabular}{|c|c|c|c|c|c|c|c|c|c|c|}
\hline \multirow[t]{22}{*}{$\begin{array}{l}\text { Allende } \\
\text { SJ101 }\end{array}$} & Mineral & $\begin{array}{c}\text { Melilite } \\
\text { Åk }\end{array}$ & ${ }^{27} \mathrm{Al} /{ }^{24} \mathrm{Mg}$ & $2 \sigma$ & $\begin{array}{c}\delta^{26} \mathrm{Mg}^{*} \\
{ }^{1} \boldsymbol{\beta}=\mathbf{0 . 5 1 2 8}\end{array}$ & $2 \sigma$ & $\delta^{25} \mathrm{Mg}$ & $2 \sigma$ & $\begin{array}{c}\delta^{26} \mathrm{Mg}^{*} \\
{ }^{1} \beta=0.511\end{array}$ & $2 \sigma$ \\
\hline & Melilite & 80.6 & 0.608 & 0.006 & 0.126 & 0.163 & -1.84 & 0.13 & 0.138 & 0.163 \\
\hline & Melilite & 85.6 & 0.426 & 0.004 & 0.000 & 0.163 & -1.32 & 0.13 & 0.009 & 0.163 \\
\hline & Melilite & 85.2 & 0.441 & 0.005 & 0.059 & 0.229 & -1.17 & 0.16 & 0.067 & 0.229 \\
\hline & Pyroxene & & 0.967 & 0.01 & 0.228 & 0.075 & -2.37 & 0.18 & 0.245 & 0.075 \\
\hline & Pyroxene & & 0.656 & 0.007 & 0.125 & 0.075 & -2.81 & 0.18 & 0.144 & 0.075 \\
\hline & Pyroxene & & 1.065 & 0.011 & 0.257 & 0.075 & -2.88 & 0.18 & 0.277 & 0.075 \\
\hline & Pyroxene & & 0.662 & 0.007 & 0.128 & 0.075 & -2.64 & 0.18 & 0.146 & 0.075 \\
\hline & Pyroxene & & 0.659 & 0.007 & 0.171 & 0.075 & -2.57 & 0.18 & 0.188 & 0.075 \\
\hline & Olivine & & $1.38 \mathrm{E}-03$ & $1.70 \mathrm{E}-05$ & -0.118 & 0.124 & -1.7 & 0.15 & -0.107 & 0.124 \\
\hline & Olivine & & $1.40 \mathrm{E}-03$ & $1.74 \mathrm{E}-05$ & -0.195 & 0.124 & -1.67 & 0.15 & -0.184 & 0.124 \\
\hline & Olivine & & $1.35 \mathrm{E}-03$ & $1.63 \mathrm{E}-05$ & -0.111 & 0.124 & -1.65 & 0.15 & -0.099 & 0.124 \\
\hline & Olivine & & $1.42 \mathrm{E}-03$ & $1.78 \mathrm{E}-05$ & -0.179 & 0.124 & -2 & 0.15 & -0.165 & 0.124 \\
\hline & Olivine & & $1.05 \mathrm{E}-03$ & $1.58 \mathrm{E}-05$ & -0.075 & 0.124 & -2.23 & 0.15 & -0.06 & 0.124 \\
\hline & Olivine & & $1.52 \mathrm{E}-03$ & $1.89 \mathrm{E}-05$ & -0.194 & 0.124 & -2.04 & 0.15 & -0.18 & 0.124 \\
\hline & Spinel & & 2.645 & 0.027 & 0.907 & 0.178 & 0.97 & 0.15 & 0.901 & 0.178 \\
\hline & Spinel & & 2.569 & 0.026 & 0.848 & 0.178 & -0.49 & 0.15 & 0.851 & 0.178 \\
\hline & Spinel & & 2.547 & 0.026 & 0.781 & 0.178 & -0.3 & 0.15 & 0.783 & 0.178 \\
\hline & Spinel & & 2.593 & 0.026 & 0.759 & 0.178 & -0.02 & 0.15 & 0.759 & 0.178 \\
\hline & Anorthite & & 179 & 3.2 & 42.7 & 3.8 & -0.5 & 2.2 & 42.7 & 3.8 \\
\hline & Anorthite & & 370 & 6.2 & 109.2 & 4.8 & -2 & 2.5 & 109.2 & 4.8 \\
\hline & Anorthite & & 237 & 3.6 & 78.3 & 3.4 & -0.1 & 2.1 & 78.3 & 3.4 \\
\hline
\end{tabular}




\begin{tabular}{|c|c|c|c|c|c|c|c|c|c|c|}
\hline $\begin{array}{l}\text { Allende } \\
\text { ALVIN }\end{array}$ & Mineral & $\begin{array}{c}\text { Melilite } \\
\text { Åk }\end{array}$ & ${ }^{27} \mathrm{Al} /{ }^{24} \mathrm{Mg}$ & $2 \sigma$ & $\begin{array}{c}\delta^{26} \mathrm{Mg}^{*} \\
\beta=0.5128\end{array}$ & $2 \sigma$ & $\delta^{25} \mathrm{Mg}$ & $2 \sigma$ & $\begin{array}{c}\delta^{26} \mathrm{Mg}^{*} \\
\beta=0.511\end{array}$ & $2 \sigma$ \\
\hline & Pyroxene & & 0.714 & 0.007 & 0.126 & 0.101 & -0.09 & 0.08 & 0.127 & 0.101 \\
\hline & Pyroxene & & 0.754 & 0.008 & 0.131 & 0.101 & 0.16 & 0.08 & 0.13 & 0.101 \\
\hline & Pyroxene & & 0.949 & 0.009 & 0.183 & 0.101 & -0.22 & 0.08 & 0.185 & 0.101 \\
\hline & Pyroxene & & 1.044 & 0.011 & 0.195 & 0.101 & -0.85 & 0.08 & 0.201 & 0.101 \\
\hline & Pyroxene & & 0.548 & 0.005 & 0.025 & 0.101 & -0.96 & 0.08 & 0.032 & 0.101 \\
\hline & Pyroxene & & 0.76 & 0.008 & 0.114 & 0.101 & -0.9 & 0.08 & 0.12 & 0.101 \\
\hline & Pyroxene & & 1.140 & 0.011 & 0.271 & 0.101 & -0.24 & 0.08 & 0.279 & 0.101 \\
\hline & Olivine & & $2.10 \mathrm{E}-03$ & $2.00 \mathrm{E}-04$ & -0.145 & 0.129 & -0.55 & 0.14 & -0.141 & 0.129 \\
\hline & Olivine & & $1.60 \mathrm{E}-03$ & $2.20 \mathrm{E}-05$ & -0.045 & 0.129 & -0.65 & 0.14 & -0.041 & 0.129 \\
\hline & Olivine & & $1.20 \mathrm{E}-03$ & $3.20 \mathrm{E}-05$ & -0.090 & 0.129 & -0.2 & 0.14 & -0.089 & 0.129 \\
\hline & Olivine & & $1.40 \mathrm{E}-03$ & $2.70 \mathrm{E}-05$ & -0.146 & 0.129 & -0.35 & 0.14 & -0.144 & 0.129 \\
\hline & Olivine & & $3.00 \mathrm{E}-02$ & $6.60 \mathrm{E}-04$ & -0.059 & 0.067 & -0.39 & 0.09 & -0.056 & 0.067 \\
\hline & Olivine & & $1.10 \mathrm{E}-03$ & $1.50 \mathrm{E}-05$ & -0.056 & 0.071 & -0.66 & 0.09 & -0.052 & 0.071 \\
\hline & Olivine & & $1.80 \mathrm{E}-03$ & $1.40 \mathrm{E}-04$ & -0.084 & 0.080 & -0.83 & 0.09 & -0.078 & 0.08 \\
\hline & Olivine & & $2.50 \mathrm{E}-03$ & 5.70E-05 & -0.124 & 0.090 & -0.42 & 0.09 & -0.121 & 0.09 \\
\hline & Spinel & & 2.567 & 0.026 & 0.631 & 0.179 & 1.94 & 0.15 & 0.618 & 0.179 \\
\hline & Spinel & & 2.553 & 0.026 & 0.769 & 0.179 & 1.36 & 0.15 & 0.76 & 0.179 \\
\hline & Spinel & & 2.549 & 0.026 & 0.597 & 0.178 & 1.31 & 0.15 & 0.588 & 0.178 \\
\hline & Spinel & & 2.535 & 0.026 & 0.652 & 0.179 & 1.91 & 0.15 & 0.639 & 0.179 \\
\hline & Spinel & & 2.603 & 0.026 & 0.778 & 0.179 & 3.45 & 0.15 & 0.755 & 0.179 \\
\hline & Melilite & 84.3 & 0.441 & 0.005 & 0.059 & 0.229 & -1.17 & 0.16 & 0.067 & 0.229 \\
\hline & Anorthite & & 617 & 33 & 6.617 & 9.166 & -1.8 & 5.8 & 6.638 & 9.166 \\
\hline
\end{tabular}




\begin{tabular}{|c|c|c|c|c|c|c|c|c|c|c|}
\hline \multirow[t]{26}{*}{$\begin{array}{l}\text { Efremovka } \\
\text { E64 }\end{array}$} & Mineral & $\begin{array}{c}\text { Melilite } \\
\text { Ák }\end{array}$ & ${ }^{27} \mathrm{Al} /{ }^{24} \mathrm{Mg}$ & $2 \sigma$ & $\begin{array}{c}\delta^{26} \mathrm{Mg}^{*} \\
\beta=0.5128\end{array}$ & $2 \sigma$ & $\delta^{25} \mathrm{Mg}$ & $2 \sigma$ & $\begin{array}{c}\delta^{26} \mathrm{Mg}^{*} \\
\beta=0.511\end{array}$ & $2 \sigma$ \\
\hline & Melilite & 30 & 5.913 & 0.06 & 2.160 & 0.479 & 1.81 & 0.24 & 2.148 & 0.479 \\
\hline & Melilite & 27.9 & 6.554 & 0.094 & 2.201 & 0.397 & 1.92 & 0.18 & 2.187 & 0.397 \\
\hline & Melilite & 39.2 & 3.924 & 0.041 & 1.809 & 0.330 & 1.76 & 0.16 & 1.797 & 0.33 \\
\hline & Melilite & 65.1 & 1.358 & 0.014 & 0.628 & 0.231 & 4.23 & 0.16 & 0.599 & 0.231 \\
\hline & Melilite & 26.7 & 6.957 & 0.078 & 2.766 & 0.421 & 3.56 & 0.18 & 2.741 & 0.421 \\
\hline & Melilite & 29.1 & 6.181 & 0.064 & 2.458 & 0.415 & 3.73 & 0.17 & 2.432 & 0.415 \\
\hline & Melilite & 29.4 & 6.069 & 0.066 & 2.084 & 0.440 & 3.93 & 0.22 & 2.057 & 0.44 \\
\hline & Pyroxene & & 1.688 & 0.017 & 0.702 & 0.103 & 9.98 & 0.08 & 0.633 & 0.103 \\
\hline & Pyroxene & & 1.604 & 0.016 & 0.688 & 0.103 & 9.85 & 0.08 & 0.619 & 0.103 \\
\hline & Pyroxene & & 1.342 & 0.014 & 0.554 & 0.103 & 10.02 & 0.08 & 0.484 & 0.103 \\
\hline & Pyroxene & & 1.257 & 0.013 & 0.597 & 0.103 & 9.94 & 0.08 & 0.528 & 0.103 \\
\hline & Pyroxene & & 0.745 & 0.008 & 0.364 & 0.103 & 9.96 & 0.08 & 0.295 & 0.103 \\
\hline & Pyroxene & & 1.291 & 0.013 & 0.568 & 0.103 & 9.6 & 0.08 & 0.501 & 0.103 \\
\hline & Pyroxene & & 0.95 & 0.01 & 0.477 & 0.103 & 9.63 & 0.08 & 0.41 & 0.103 \\
\hline & Olivine & & $2.20 \mathrm{E}-03$ & $3.70 \mathrm{E}-05$ & 0.110 & 0.132 & 11.31 & 0.14 & 0.031 & 0.132 \\
\hline & Olivine & & $2.30 \mathrm{E}-03$ & $4.30 \mathrm{E}-05$ & 0.053 & 0.132 & 11.26 & 0.14 & -0.026 & 0.132 \\
\hline & Olivine & & $1.80 \mathrm{E}-03$ & $3.00 \mathrm{E}-05$ & 0.010 & 0.132 & 11.22 & 0.14 & -0.068 & 0.132 \\
\hline & Olivine & & $2.70 \mathrm{E}-03$ & $6.60 \mathrm{E}-05$ & 0.099 & 0.132 & 11.25 & 0.14 & 0.02 & 0.132 \\
\hline & Spinel & & 2.555 & 0.026 & 1.125 & 0.133 & 6.79 & 0.09 & 1.078 & 0.133 \\
\hline & Spinel & & 2.569 & 0.026 & 1.063 & 0.133 & 6.55 & 0.09 & 1.017 & 0.133 \\
\hline & Spinel & & 2.543 & 0.026 & 1.041 & 0.134 & 13.84 & 0.09 & 0.944 & 0.134 \\
\hline & Spinel & & 2.565 & 0.026 & 1.021 & 0.134 & 13.21 & 0.09 & 0.929 & 0.134 \\
\hline & Anorthite & & 336 & 4 & 1.816 & 10.372 & 1.58 & 5.5 & 1.805 & 10.372 \\
\hline & Anorthite & & 1095 & 24 & -5.095 & 20.834 & 9.57 & 10.94 & -5.162 & 20.834 \\
\hline & Anorthite & & 576 & 24 & 12.729 & 16.589 & -5 & 8.3 & 12.763 & 16.589 \\
\hline
\end{tabular}




\begin{tabular}{|c|c|c|c|c|c|c|c|c|c|c|}
\hline \multirow[t]{31}{*}{$\begin{array}{c}\text { Efremovka } \\
\text { E60 }\end{array}$} & Mineral & 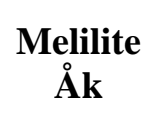 & ${ }^{27} \mathrm{Al} /{ }^{24} \mathrm{Mg}$ & $2 \sigma$ & $\begin{array}{c}\delta^{26} \mathrm{Mg}^{*} \\
\beta=0.5128\end{array}$ & $2 \sigma$ & $\delta^{25} \mathrm{Mg}$ & $2 \sigma$ & $\begin{array}{c}\delta^{26} \mathrm{Mg}^{*} \\
\beta=0.511\end{array}$ & $2 \sigma$ \\
\hline & Melilite & 84.1 & 0.479 & 0.005 & 0.194 & 0.101 & 1.92 & 0.10 & 0.180 & 0.101 \\
\hline & Melilite & 85.2 & 0.440 & 0.004 & 0.126 & 0.101 & 1.91 & 0.10 & 0.113 & 0.101 \\
\hline & Melilite & 79.8 & 0.641 & 0.010 & 0.257 & 0.101 & 1.95 & 0.10 & 0.244 & 0.101 \\
\hline & Melilite & 83.9 & 0.485 & 0.006 & 0.448 & 0.137 & 1.56 & 0.19 & 0.438 & 0.137 \\
\hline & Melilite & 79.8 & 0.640 & 0.008 & 0.386 & 0.138 & 1.92 & 0.19 & 0.373 & 0.138 \\
\hline & Melilite & 80.7 & 0.607 & 0.006 & 0.345 & 0.138 & 2.19 & 0.19 & 0.329 & 0.138 \\
\hline & Melilite & 79.9 & 0.637 & 0.006 & 0.346 & 0.137 & 1.34 & 0.19 & 0.337 & 0.137 \\
\hline & Melilite & 85.0 & 0.448 & 0.004 & 0.280 & 0.138 & 2.86 & 0.19 & 0.260 & 0.138 \\
\hline & Melilite & 84.1 & 0.478 & 0.005 & 0.201 & 0.138 & 2.79 & 0.19 & 0.182 & 0.138 \\
\hline & Melilite & 78.7 & 0.687 & 0.008 & 0.278 & 0.137 & 0.06 & 0.19 & 0.278 & 0.137 \\
\hline & Melilite & 72.0 & 0.985 & 0.010 & 0.326 & 0.101 & 1.76 & 0.10 & 0.314 & 0.101 \\
\hline & Melilite & 60.4 & 1.659 & 0.017 & 0.687 & 0.138 & 2.78 & 0.19 & 0.668 & 0.138 \\
\hline & Melilite & 30.9 & 5.656 & 0.057 & 2.134 & 0.137 & -0.17 & 0.19 & 2.135 & 0.137 \\
\hline & Melilite & 30.4 & 5.806 & 0.059 & 1.956 & 0.165 & -0.33 & 0.19 & 1.958 & 0.165 \\
\hline & Melilite & 15.0 & 14.39 & 0.15 & 5.65 & 0.99 & -1.1 & 0.5 & 5.65 & 0.99 \\
\hline & Melilite & 15.7 & 13.61 & 0.15 & 5.32 & 1.09 & -0.8 & 0.6 & 5.32 & 1.09 \\
\hline & Melilite & 15.9 & 13.37 & 0.14 & 5.49 & 1.01 & 0.1 & 0.5 & 5.49 & 1.01 \\
\hline & Melilite & 15.1 & 14.24 & 0.14 & 5.13 & 1.03 & -0.8 & 0.6 & 5.13 & 1.03 \\
\hline & Melilite & 23.8 & 8.09 & 0.09 & -0.61 & 1.10 & 4.5 & 0.6 & -0.61 & 1.10 \\
\hline & Pyroxene & & 0.934 & 0.009 & 0.252 & 0.067 & 4.01 & 0.06 & 0.225 & 0.067 \\
\hline & Pyroxene & & 1.062 & 0.011 & 0.280 & 0.068 & 3.93 & 0.06 & 0.253 & 0.068 \\
\hline & Pyroxene & & 0.931 & 0.011 & 0.238 & 0.068 & 4.10 & 0.06 & 0.210 & 0.068 \\
\hline & Pyroxene & & 1.283 & 0.013 & 0.467 & 0.073 & 2.60 & 0.06 & 0.450 & 0.073 \\
\hline & Pyroxene & & 1.186 & 0.013 & 0.421 & 0.065 & 3.79 & 0.06 & 0.394 & 0.065 \\
\hline & Pyroxene & & 0.491 & 0.005 & 0.157 & 0.065 & 4.00 & 0.06 & 0.129 & 0.065 \\
\hline & Olivine & & $6.29 \mathrm{E}-03$ & $4.96 \mathrm{E}-04$ & -0.086 & 0.106 & 4.48 & 0.08 & -0.117 & 0.106 \\
\hline & Olivine & & $1.40 \mathrm{E}-03$ & $2.93 \mathrm{E}-05$ & -0.064 & 0.106 & 4.42 & 0.08 & -0.095 & 0.106 \\
\hline & Olivine & & $2.61 \mathrm{E}-03$ & 7.02E-05 & -0.129 & 0.106 & 4.52 & 0.08 & -0.160 & 0.106 \\
\hline & Olivine & & $4.76 \mathrm{E}-03$ & $3.55 \mathrm{E}-04$ & -0.133 & 0.106 & 4.14 & 0.08 & -0.162 & 0.106 \\
\hline & Spinel & & 2.567 & 0.026 & 0.875 & 0.118 & 4.88 & 0.16 & 0.841 & 0.118 \\
\hline
\end{tabular}




$\begin{array}{ccccccccc}\text { Spinel } & 2.558 & 0.026 & 0.835 & 0.106 & 4.75 & 0.16 & 0.803 & 0.106 \\ \text { Spinel } & 2.559 & 0.026 & 0.866 & 0.128 & 4.85 & 0.16 & 0.832 & 0.128 \\ \text { Spinel } & 2.544 & 0.026 & 0.915 & 0.096 & 5.32 & 0.16 & 0.878 & 0.096 \\ \text { Spinel } & 2.557 & 0.026 & 0.911 & 0.087 & 4.80 & 0.16 & 0.878 & 0.087 \\ \text { Anorthite } & 237 & 3 & 62.7 & 2.7 & 2.53 & 1.41 & 62.7 & 2.7 \\ \text { Anorthite } & 219 & 9 & 39.0 & 3.9 & 3.95 & 1.79 & 39.0 & 3.9\end{array}$




\begin{tabular}{|c|c|c|c|c|c|c|c|c|c|c|}
\hline \multirow[t]{31}{*}{$\begin{array}{c}\text { Vigarano } \\
\text { 3137-2 }\end{array}$} & Mineral & $\begin{array}{c}\text { Melilite } \\
\text { Ák }\end{array}$ & ${ }^{27} \mathrm{Al} /{ }^{24} \mathrm{Mg}$ & $2 \sigma$ & $\begin{array}{c}\delta^{26} \mathrm{Mg}^{*} \\
\beta=0.5128\end{array}$ & $2 \sigma$ & $\delta^{25} \mathrm{Mg}$ & $2 \sigma$ & $\begin{array}{c}\delta^{26} \mathrm{Mg}^{*} \\
\beta=0.511\end{array}$ & $2 \sigma$ \\
\hline & Melilite & 86.6 & 0.393 & 0.004 & 0.185 & 0.080 & 6.33 & 0.12 & 0.141 & 0.08 \\
\hline & Melilite & 85.8 & 0.42 & 0.004 & 0.140 & 0.080 & 6.39 & 0.12 & 0.096 & 0.08 \\
\hline & Melilite & 84.2 & 0.477 & 0.005 & 0.212 & 0.080 & 6.57 & 0.12 & 0.166 & 0.08 \\
\hline & Melilite & 86.1 & 0.408 & 0.004 & 0.125 & 0.080 & 6.63 & 0.12 & 0.079 & 0.08 \\
\hline & Melilite & 86.2 & 0.407 & 0.004 & 0.280 & 0.080 & 6.53 & 0.12 & 0.235 & 0.08 \\
\hline & Melilite & 86.9 & 0.381 & 0.004 & 0.142 & 0.080 & 6.27 & 0.12 & 0.098 & 0.08 \\
\hline & Melilite & 85.5 & 0.429 & 0.004 & 0.214 & 0.080 & 6.59 & 0.12 & 0.168 & 0.08 \\
\hline & Melilite & 87.6 & 0.357 & 0.004 & 0.158 & 0.102 & 6.27 & 0.1 & 0.115 & 0.102 \\
\hline & Melilite & 87.9 & 0.348 & 0.003 & 0.340 & 0.102 & 6.06 & 0.1 & 0.298 & 0.102 \\
\hline & Melilite & 86.1 & 0.408 & 0.004 & 0.117 & 0.102 & 6.48 & 0.1 & 0.072 & 0.102 \\
\hline & Melilite & 82.8 & 0.525 & 0.005 & 0.156 & 0.102 & 6.82 & 0.1 & 0.109 & 0.102 \\
\hline & Melilite & 86.1 & 0.408 & 0.004 & 0.157 & 0.102 & 6.69 & 0.1 & 0.111 & 0.102 \\
\hline & Melilite & 86.3 & 0.403 & 0.004 & 0.075 & 0.102 & 6.05 & 0.1 & 0.033 & 0.102 \\
\hline & Melilite & 68.3 & 1.173 & 0.012 & 0.442 & 0.080 & 6.6 & 0.12 & 0.396 & 0.08 \\
\hline & Melilite & 62 & 1.55 & 0.016 & 0.443 & 0.080 & 6.88 & 0.12 & 0.395 & 0.08 \\
\hline & Melilite & 57.2 & 1.894 & 0.019 & 0.640 & 0.097 & 6.72 & 0.12 & 0.593 & 0.097 \\
\hline & Melilite & 52.6 & 2.281 & 0.023 & 0.696 & 0.107 & 6.81 & 0.12 & 0.648 & 0.107 \\
\hline & Melilite & 51.1 & 2.422 & 0.024 & 0.824 & 0.093 & 6.75 & 0.12 & 0.778 & 0.093 \\
\hline & Melilite & 60.9 & 1.622 & 0.016 & 0.618 & 0.102 & 7.49 & 0.1 & 0.566 & 0.102 \\
\hline & Melilite & 61 & 1.616 & 0.016 & 0.645 & 0.102 & 7.39 & 0.1 & 0.594 & 0.102 \\
\hline & Pyroxene & & 1.117 & 0.012 & 0.365 & 0.076 & 5.99 & 0.18 & 0.324 & 0.076 \\
\hline & Pyroxene & & 1.066 & 0.011 & 0.316 & 0.076 & 6 & 0.18 & 0.274 & 0.076 \\
\hline & Pyroxene & & 0.613 & 0.006 & 0.174 & 0.066 & 6.38 & 0.06 & 0.13 & 0.066 \\
\hline & Pyroxene & & 1.293 & 0.013 & 0.460 & 0.068 & 6.1 & 0.06 & 0.418 & 0.068 \\
\hline & Pyroxene & & 0.964 & 0.011 & 0.351 & 0.066 & 6.16 & 0.06 & 0.308 & 0.066 \\
\hline & Pyroxene & & 0.6 & 0.006 & 0.183 & 0.066 & 6.32 & 0.06 & 0.139 & 0.066 \\
\hline & Olivine & & $1.20 \mathrm{E}-03$ & $2.80 \mathrm{E}-$ & 0.114 & 0.131 & 6.15 & 0.14 & 0.072 & 0.131 \\
\hline & Olivine & & $1.60 \mathrm{E}-03$ & $2 . \overline{40 \mathrm{E}-}$ & -0.071 & 0.131 & 5.85 & 0.14 & -0.111 & 0.131 \\
\hline & Olivine & & $1.30 \mathrm{E}-03$ & $3.30 \mathrm{E}-$ & -0.035 & 0.131 & 6.02 & 0.14 & -0.076 & 0.131 \\
\hline & Olivine & & $1.30 \mathrm{E}-03$ & $1.60 \mathrm{E}-$ & -0.012 & 0.131 & 5.81 & 0.14 & -0.052 & 0.131 \\
\hline
\end{tabular}




$\begin{array}{ccccccccc}\text { Spinel } & 2.566 & 0.026 & 0.969 & 0.133 & 8.51 & 0.09 & 0.91 & 0.133 \\ \text { Spinel } & 2.532 & 0.025 & 0.800 & 0.133 & 8.51 & 0.09 & 0.741 & 0.133 \\ \text { Spinel } & 2.539 & 0.026 & 0.820 & 0.133 & 8.69 & 0.09 & 0.76 & 0.133 \\ \text { Spinel } & 2.556 & 0.026 & 0.801 & 0.133 & 8.13 & 0.09 & 0.744 & 0.133 \\ \text { Spinel } & 2.555 & 0.026 & 0.854 & 0.133 & 8.16 & 0.09 & 0.798 & 0.133 \\ \text { Spinel } & 2.542 & 0.026 & 0.934 & 0.133 & 8.56 & 0.09 & 0.874 & 0.133 \\ \text { Anorthite } & 321 & 11 & 4.566 & 4.225 & 5.1 & 2.3 & 4.531 & 4.225 \\ \text { Anorthite } & 962 & 13 & 2.884 & 5.028 & 7 & 2.8 & 2.835 & 5.028\end{array}$




\begin{tabular}{|c|c|c|c|c|c|c|c|c|c|c|}
\hline $\begin{array}{c}\text { Allende } \\
\text { TS35-F1 }\end{array}$ & Mineral & $\begin{array}{c}\text { Melilite } \\
\text { Ák }\end{array}$ & ${ }^{27} \mathrm{Al} /{ }^{24} \mathrm{Mg}$ & $2 \sigma$ & $\begin{array}{c}\delta^{26} \mathrm{Mg}^{*} \\
\beta=0.5128\end{array}$ & $2 \sigma$ & $\delta^{25} \mathrm{Mg}$ & $2 \sigma$ & $\begin{array}{c}\delta^{26} \mathrm{Mg}^{*} \\
\beta=0.511\end{array}$ & $2 \sigma$ \\
\hline & Melilite & 17.9 & 11.59 & 0.12 & 3.428 & 0.548 & 7.32 & 0.25 & 3.377 & 0.548 \\
\hline & Melilite & 17 & 12.39 & 0.12 & 4.245 & 0.733 & 6.44 & 0.32 & 4.2 & 0.733 \\
\hline & Melilite & 8.7 & 26.7 & 0.3 & 9.010 & 1.662 & 4.5 & 0.9 & 8.978 & 1.662 \\
\hline & Melilite & 8.8 & 26.3 & 0.5 & 7.263 & 1.429 & 6.08 & 0.81 & 7.221 & 1.429 \\
\hline & Melilite & 20.2 & 9.99 & 0.12 & 3.593 & 1.731 & 7.41 & 0.88 & 3.542 & 1.731 \\
\hline & Melilite & 24.7 & 7.71 & 0.08 & 2.550 & 1.001 & 5.97 & 0.57 & 2.508 & 1.001 \\
\hline & Pyroxene & & 0.739 & 0.008 & 0.154 & 0.075 & -0.02 & 0.18 & 0.154 & 0.075 \\
\hline & Pyroxene & & 1.005 & 0.01 & 0.294 & 0.075 & 0.13 & 0.18 & 0.293 & 0.075 \\
\hline & Pyroxene & & 0.947 & 0.01 & 0.258 & 0.075 & -0.14 & 0.18 & 0.259 & 0.075 \\
\hline & Pyroxene & & 1.077 & 0.011 & 0.270 & 0.076 & 1.07 & 0.18 & 0.263 & 0.076 \\
\hline & Pyroxene & & 1.284 & 0.013 & 0.381 & 0.075 & 0.41 & 0.18 & 0.378 & 0.075 \\
\hline & Pyroxene & & 0.847 & 0.009 & 0.263 & 0.076 & 1.74 & 0.18 & 0.251 & 0.076 \\
\hline & Pyroxene & & 0.939 & 0.01 & 0.293 & 0.076 & 1.66 & 0.18 & 0.282 & 0.076 \\
\hline & Olivine & & $1.30 \mathrm{E}-03$ & $1.60 \mathrm{E}-05$ & -0.180 & 0.125 & 1.337 & 0.145 & -0.189 & 0.125 \\
\hline & Olivine & & $1.10 \mathrm{E}-03$ & $1.90 \mathrm{E}-05$ & -0.091 & 0.125 & 1.352 & 0.145 & -0.101 & 0.125 \\
\hline & Olivine & & $1.20 \mathrm{E}-03$ & $1.70 \mathrm{E}-05$ & -0.090 & 0.125 & 1.373 & 0.145 & -0.1 & 0.125 \\
\hline & Olivine & & $1.10 \mathrm{E}-03$ & $1.60 \mathrm{E}-05$ & -0.124 & 0.125 & 1.383 & 0.145 & -0.134 & 0.125 \\
\hline & Olivine & & $7.00 \mathrm{E}-03$ & $1.20 \mathrm{E}-04$ & -0.084 & 0.125 & 1.209 & 0.145 & -0.092 & 0.125 \\
\hline & Olivine & & $1.70 \mathrm{E}-03$ & $1.30 \mathrm{E}-04$ & -0.171 & 0.124 & 0.372 & 0.145 & -0.174 & 0.124 \\
\hline & Spinel & & 2.572 & 0.026 & 0.738 & 0.129 & 2.82 & 0.09 & 0.719 & 0.129 \\
\hline & Spinel & & 2.578 & 0.026 & 0.815 & 0.129 & 3.28 & 0.09 & 0.792 & 0.129 \\
\hline & Spinel & & 2.589 & 0.026 & 0.929 & 0.130 & 9.19 & 0.09 & 0.865 & 0.13 \\
\hline & Spinel & & 2.554 & 0.026 & 0.774 & 0.129 & 2.6 & 0.09 & 0.756 & 0.129 \\
\hline & Spinel & & 2.567 & 0.026 & 0.790 & 0.129 & 2.54 & 0.09 & 0.772 & 0.129 \\
\hline & Spinel & & 2.562 & 0.026 & 0.795 & 0.129 & 3.48 & 0.09 & 0.771 & 0.129 \\
\hline & Anorthite & & 444 & 14 & 14.482 & 6.949 & 10.7 & 4.3 & 14.408 & 6.949 \\
\hline & Anorthite & & 665 & 22 & 1.538 & 6.950 & 5.1 & 4.2 & 1.503 & 6.95 \\
\hline & Anorthite & & 792 & 31 & 8.961 & 6.485 & 2.4 & 4.5 & 8.944 & 6.485 \\
\hline
\end{tabular}




\begin{tabular}{|c|c|c|c|c|c|c|c|c|c|c|}
\hline \multirow[t]{23}{*}{$\begin{array}{c}\text { NWA-3118 } \\
\text { 4N }\end{array}$} & Mineral & $\begin{array}{c}\text { Melilite } \\
\text { Åk }\end{array}$ & ${ }^{27} \mathrm{Al} /{ }^{24} \mathrm{Mg}$ & $2 \sigma$ & $\begin{array}{c}\delta^{26} \mathrm{Mg}^{*} \\
\beta=0.5128\end{array}$ & $2 \sigma$ & $\delta^{25} \mathrm{Mg}$ & $2 \sigma$ & $\begin{array}{c}\delta^{26} \mathrm{Mg}^{*} \\
\beta=0.511\end{array}$ & $2 \sigma$ \\
\hline & Pyroxene & & 1.024 & 0.01 & 0.309 & 0.079 & 0.22 & 0.09 & 0.308 & 0.079 \\
\hline & Pyroxene & & 1.056 & 0.012 & 0.385 & 0.079 & 0.15 & 0.09 & 0.384 & 0.079 \\
\hline & Pyroxene & & 0.984 & 0.01 & 0.361 & 0.079 & 0.21 & 0.09 & 0.359 & 0.079 \\
\hline & Pyroxene & & 0.636 & 0.006 & 0.192 & 0.079 & 0.2 & 0.09 & 0.191 & 0.079 \\
\hline & Pyroxene & & 0.976 & 0.01 & 0.312 & 0.079 & 0.15 & 0.09 & 0.311 & 0.079 \\
\hline & Pyroxene & & 1.301 & 0.013 & 0.433 & 0.079 & 0.19 & 0.09 & 0.432 & 0.079 \\
\hline & Pyroxene & & 0.695 & 0.007 & 0.205 & 0.079 & 0.05 & 0.09 & 0.205 & 0.079 \\
\hline & Olivine & & $1.70 \mathrm{E}-03$ & $2.50 \mathrm{E}-05$ & -0.018 & 0.086 & 0.22 & 0.09 & -0.019 & 0.086 \\
\hline & Olivine & & $2.00 \mathrm{E}-03$ & $2.80 \mathrm{E}-05$ & -0.011 & 0.078 & 0.35 & 0.09 & -0.014 & 0.078 \\
\hline & Olivine & & $2.90 \mathrm{E}-03$ & $1.40 \mathrm{E}-04$ & 0.031 & 0.069 & 0.37 & 0.09 & 0.029 & 0.069 \\
\hline & Olivine & & $1.90 \mathrm{E}-03$ & $2.40 \mathrm{E}-05$ & -0.055 & 0.088 & 0.42 & 0.09 & -0.058 & 0.088 \\
\hline & Olivine & & $1.50 \mathrm{E}-03$ & $2.10 \mathrm{E}-05$ & 0.006 & 0.068 & 0.17 & 0.09 & 0.005 & 0.068 \\
\hline & Olivine & & $2.40 \mathrm{E}-03$ & $8.60 \mathrm{E}-05$ & 0.018 & 0.106 & 0.31 & 0.09 & 0.016 & 0.106 \\
\hline & Spinel & & 2.537 & 0.026 & 0.821 & 0.105 & 2.75 & 0.16 & 0.802 & 0.105 \\
\hline & Spinel & & 2.538 & 0.026 & 0.825 & 0.109 & 2.65 & 0.16 & 0.807 & 0.109 \\
\hline & Spinel & & 2.544 & 0.026 & 0.828 & 0.137 & 2.95 & 0.16 & 0.808 & 0.137 \\
\hline & Spinel & & 2.534 & 0.026 & 0.906 & 0.093 & 2.49 & 0.16 & 0.888 & 0.093 \\
\hline & Spinel & & 2.541 & 0.026 & 0.844 & 0.140 & 2.68 & 0.16 & 0.825 & 0.14 \\
\hline & Anorthite & & 292 & 5 & 74.350 & 2.267 & 0 & 1.1 & 74.35 & 2.267 \\
\hline & Anorthite & & 243 & 4 & 76.699 & 3.020 & 1.5 & 1.5 & 76.689 & 3.02 \\
\hline & Anorthite & & 191 & 2 & 49.283 & 1.932 & 1.5 & 1.1 & 49.272 & 1.932 \\
\hline & Anorthite & & 480 & 20 & 33.592 & 4.816 & 0.7 & 2.6 & 33.587 & 4.816 \\
\hline
\end{tabular}

${ }^{1} \delta^{26} \mathrm{Mg} *$ is calculated two ways, using $\beta=0.5128$ (column 6; plotted in figures) and $\beta=0.511$ (column 10; for comparison) 